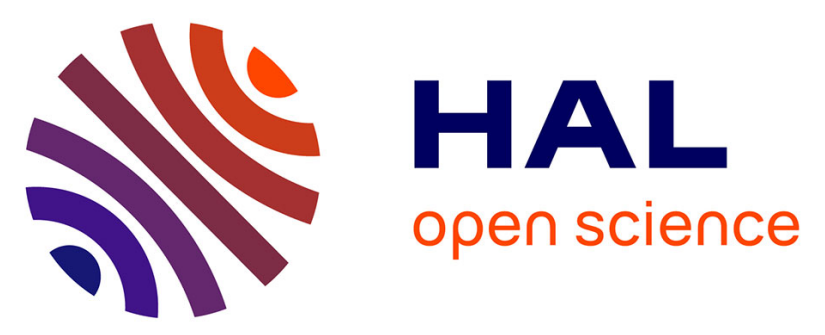

\title{
Evaluation of affinity sensor response kinetics towards dimeric ligands linked with spacers of different rigidity: Immobilized recombinant granulocyte colony-stimulating factor based synthetic receptor binding with genetically engineered dimeric analyte derivatives
}

Ieva Plikusiene, Zigmas Balevicius, Almira Ramanaviciene, Julian Talbot, Gitana Mickiene, Saulius Balevicius, Arunas Stirke, Alla Tereshchenko, Linas Tamosaitis, Gintautas Zvirblis, et al.

\section{To cite this version:}

Ieva Plikusiene, Zigmas Balevicius, Almira Ramanaviciene, Julian Talbot, Gitana Mickiene, et al.. Evaluation of affinity sensor response kinetics towards dimeric ligands linked with spacers of different rigidity: Immobilized recombinant granulocyte colony-stimulating factor based synthetic receptor binding with genetically engineered dimeric analyte derivatives. Biosensors and Bioelectronics, 2020, 156, pp.112112. 10.1016/j.bios.2020.112112 . hal-03087174

\author{
HAL Id: hal-03087174 \\ https://hal.science/hal-03087174
}

Submitted on 5 Jan 2021

HAL is a multi-disciplinary open access archive for the deposit and dissemination of scientific research documents, whether they are published or not. The documents may come from teaching and research institutions in France or abroad, or from public or private research centers.
L'archive ouverte pluridisciplinaire HAL, est destinée au dépôt et à la diffusion de documents scientifiques de niveau recherche, publiés ou non, émanant des établissements d'enseignement et de recherche français ou étrangers, des laboratoires publics ou privés. 
I. Plikusiene, Z. Balevicius, A. Ramanaviciene, J. Talbot, G. Mickiene, S. Balevicius, A. Stirke, A. Tereshchenko, L. Tamosaitis, G. Zvirblis, A. Ramanavicius, Evaluation of affinity sensor response kinetics towards dimeric ligands linked with spacers of different rigidity: Immobilized recombinant granulocyte colony-stimulating factor based synthetic receptor binding with genetically engineered dimeric analyte d. Biosens. Bioelectron. 156, 112112 (2020). doi: https://doi.org/10.1016/j.bios.2020.112112

Journal version is available:

https://www.sciencedirect.com/science/article/abs/pii/S0956566320301093

\section{Evaluation of affinity sensor response kinetics towards dimeric ligands linked with spacers of different rigidity: immobilized recombinant granulocyte colony-stimulating factor based synthetic receptor binding with genetically engineered dimeric analyte derivatives}

Ieva Plikusiene $\mathrm{e}^{[\mathrm{a}, \mathrm{b}]}$, Zigmas Balevicius ${ }^{[\mathrm{a}, \mathrm{e}]}$, Almira Ramanaviciene ${ }^{[\mathrm{d}]}$, Julian Talbot ${ }^{[\mathrm{f}]}$, Gitana Mickiene $^{[\mathrm{c}]}$, Saulius Balevicius ${ }^{[\mathrm{a}]}$, Arunas Stirke ${ }^{[\mathrm{a}]}$, Alla Tereshchenko $^{[\mathrm{b}, \mathrm{g}]}$, Linas Tamosaitis $^{[\mathrm{b}]}$, Gintautas Zvirblis $^{[\mathrm{c}]}$, Arunas Ramanavicius ${ }^{[\mathrm{a}, \mathrm{b},] *}$

\footnotetext{
a. Laboratory of Nanotechnology, State Research Institute Center for Physical Sciences and Technology, Vilnius, Lithuania

b. Department of Physical Chemistry, Institute of chemistry, Faculty of Chemistry and Geosciences, Vilnius University, Naugarduko 24, Vilnius Lithuania;

c. $\quad$ Life Sciences Center, Vilnius University, Sauletekio ave. 7, 10257 Vilnius, Lithuania.

d. NanoTechnas - Centre of Nanotechnology and Materials Science, Vilnius University, Naugarduko 24, Vilnius Lithuania;

e. $\quad$ Faculty of Electronics, Vilnius Gediminas Technical University, Naugarduko 41, 03227 Vilnius, Lithuania.

f. $\quad$ CNRS, Laboratoire de Physique Théorique de la Matière Condensée, Sorbonne Université.

g. Department of Experimental Physics, Faculty of Mathematics, Physics and Information Technologies, Odesa National I.I. Mechnikov University, Odesa, Ukraine.
}

* Corresponding author is Prof. habil dr. Arunas Ramanavicius e-mail: arunas.ramanavicius@chf.vu.lt 
I. Plikusiene, Z. Balevicius, A. Ramanaviciene, J. Talbot, G. Mickiene, S. Balevicius, A. Stirke, A. Tereshchenko, L. Tamosaitis, G. Zvirblis, A. Ramanavicius, Evaluation of affinity sensor response kinetics towards dimeric ligands linked with spacers of different rigidity: Immobilized recombinant granulocyte colony-stimulating factor based synthetic receptor binding with genetically engineered dimeric analyte d. Biosens. Bioelectron. 156, 112112 (2020). doi: https://doi.org/10.1016/j.bios.2020.112112

Journal version is available:

https://www.sciencedirect.com/science/article/abs/pii/S0956566320301093

\begin{abstract}
The modelling of protein-protein binding kinetics is important for the development of affinitysensors and the prediction of signaling protein based drug efficiency. Therefore, in this research we have evaluated the binding kinetics of several genetically designed protein models: (i) three different ligands based on granulocyte colony-stimulating factor GCSF homo-dimeric derivatives linked by differed by linkers of different length and flexibility; (ii) an antibody-like receptor (GCSF-R) based on two GCSF-receptor sites immobilized to Fc domains, which are common parts of protein structures forming antibodies. Genetically engineered GCSF-R is similar to an antibody because it, like the antibody, has two binding sites, which both selectively bind with GCSF ligands. To design the affinity sensor model studied here, GCSF$\mathrm{R}$ was immobilized on a thin gold layer via self-assembled monolayer conjugated with ProteinG. Binding kinetics between immobilized GCSF-R and all three different recombinant GCSFbased homo-dimeric derivatives were evaluated by total internal reflection ellipsometry. Association constants were determined by fitting mathematical models to the experimental data. It was clearly observed that both (i) affinity and (ii) binding kinetics depend on the length and flexibility of the linker that connects both domains of a GCSF-based ligand. The fastest association between immobilized GCSF-R and GCSF-based ligands was observed for ligands whose GCSF domains were interconnected by the longest and the most flexible linker. Here we present ellipsometry-based measurements and models of the interaction kinetics that advance the understanding of bidentate-receptor-based immunosensor action and enables us to predict the optimal linker structure for the design of GCSF-based medications.
\end{abstract}

Keywords: Affinity sensors; Optical immunosensors; Protein binding kinetics; Total internal reflection ellipsometry (TIRE); Drug design; Genetically modified receptors; Genetically modified ligands; Mathematical modelling; Interaction kinetics; Granulocyte colonystimulating factor (GCSF). 
I. Plikusiene, Z. Balevicius, A. Ramanaviciene, J. Talbot, G. Mickiene, S. Balevicius, A. Stirke, A. Tereshchenko, L. Tamosaitis, G. Zvirblis, A. Ramanavicius, Evaluation of affinity sensor response kinetics towards dimeric ligands linked with spacers of different rigidity: Immobilized recombinant granulocyte colony-stimulating factor based synthetic receptor binding with genetically engineered dimeric analyte d. Biosens. Bioelectron. 156, 112112 (2020). doi: https://doi.org/10.1016/j.bios.2020.112112

Journal version is available:

https://www.sciencedirect.com/science/article/abs/pii/S0956566320301093

\section{Introduction}

The development of new protein-based drugs and receptor-based or immuno-analytical systems (e.g. immunosensors and other affinity sensors) requires a deep understanding of protein-protein interaction (Ramanavicius et al., 2014). In addition to this receptor-based problem, the modelling of receptor-ligand interaction is an important issue in the development of protein-based pharmaceutics, because recently many pharmacological technologies have been focused on the improvement of the first-generation protein drugs based on the desired pharmacokinetic properties (Mitchell et al., 2016). Here protein fusion technology (PFT) can be applied, which enables the construction of larger molecular-weight proteins with combined functions. These fused multimeric proteins can be more effective than monomeric proteins due to their increased biological activity and/or prolonged duration of circulation in the blood. This has been demonstrated for multimeric erythropoietin derivatives cytokine-antibody complexes, and recombinant human granulocyte colony-stimulating factor (GCSF)-based dimeric derivative. Sometimes such fused proteins are characterized by much faster refolding, as is the case for PDGF fusion dimers (Thomason et al., 1994) and orally delivered pharmaceuticals such as GCSF-transferrin (Chen et al., 2011). Therefore, with the advancement of biotechnology, protein fusion technology will play an increasingly significant role in drug design. Among several of the above mentioned drugs designed by protein fusion technology, granulocyte colony-stimulating factor (GCSF) is an important biotechnological drug that is in the top ten of biopharmaceutical sales (Huggett et al., 2011). This protein belongs to the class of cytokines and acts on the ability of neutrophils to selectively stimulate the proliferation and differentiation of committed progenitor cells and the activation of mature neutrophils (Foote and Morstyn, 2009). Protein function technology is improving therapeutic properties of protein drugs, but most of these properties are revealed only in the late stages of drug design (Mickiene et al., 2017). Therefore, the rational design of protein and quantitative analysis of the interaction between newly designed proteins and their binding receptor remains a challenging and important problem, because quantitative methods for the evaluation of the drug efficiency are still not well established and unified. 
I. Plikusiene, Z. Balevicius, A. Ramanaviciene, J. Talbot, G. Mickiene, S. Balevicius, A. Stirke, A. Tereshchenko, L. Tamosaitis, G. Zvirblis, A. Ramanavicius, Evaluation of affinity sensor response kinetics towards dimeric ligands linked with spacers of different rigidity: Immobilized recombinant granulocyte colony-stimulating factor based synthetic receptor binding with genetically engineered dimeric analyte d. Biosens. Bioelectron. 156, 112112 (2020). doi: https://doi.org/10.1016/j.bios.2020.112112

Journal version is available:

https://www.sciencedirect.com/science/article/abs/pii/S0956566320301093

Various methods of analytical signal registration and mathematical modeling can be applied to investigate protein-protein interaction. In order to efficiently investigate proteinprotein interaction kinetics, the development of advanced, label-free analytical methods, which are suitable for the evaluation of protein binding to their receptors, is in great demand. Therefore. in this area of research special attention is paid to the application of advanced labelfree and non-destructive optical methods, which are suitable for the evaluation of proteinprotein interaction mechanisms. One of these, which is label-free and extremely sensitive, is total internal reflection ellipsometry (TIRE). TIRE is based on the registration detection of changes of light polarization when light is reflected from a solid interface (Nabok et al., 2006). The determined ellipsometric parameters psi $(\Psi)$ and delta $(\Delta)$ correspond to the ratio of amplitude and the phase shift of $\mathrm{p}$ - and s-components of polarized light respectively. As was shown by other researchers (Nabok et al., 2006, Moirangthem et al., 2010), TIRE is more sensitive than conventional SPR. The advantages of TIRE are mainly based on the determination of phase s $(\Delta)$ changes (Arwin et al., 2008, Arwin et al., 2014) because the parameter ' $\Delta$ ' varies more significantly than the function ' $\tan \Psi$ '. Thus any changes on the sensing surface induce more significant changes in the ellipsometric parameter ' $\Delta$ ' than to ' $\Psi^{\prime}$. Even 'the typical plasmonic curve' with minima in ellipsometric parameters ' $\Psi$ ', which reassemble the conventional SPR reflectance minima has a higher sensitivity, because the ' $\Psi$ ' plasmonic curve is close to square root of SPR reflectance and in fact it is 'sharper' than corresponding SPR minima registered during intensity measurement (Poksinski et al., 2004). TIRE is well suited to measurements of binding kinetics of proteins and it provides very high accuracy (Berlind et al., 2010; Balevicius et al., 2014). TIRE utilizes the analytical performance of spectroscopic ellipsometry and increases the sensitivity by introducing the surface plasmon resonance (SPR) effect into the operational scheme of ellipsometer (Baleviciute et al., 2013). Large sensitivity of TIRE enables one to analyze in detail both the structure and the formation kinetics of protein-based complexes (Balevicius et al., 2013).

Modelling of interaction between receptor and ligand can be performed by evaluating the analytical signal. This method is valuable when one wishes to evaluate the efficiency of 
I. Plikusiene, Z. Balevicius, A. Ramanaviciene, J. Talbot, G. Mickiene, S. Balevicius, A. Stirke, A. Tereshchenko, L. Tamosaitis, G. Zvirblis, A. Ramanavicius, Evaluation of affinity sensor response kinetics towards dimeric ligands linked with spacers of different rigidity: Immobilized recombinant granulocyte colony-stimulating factor based synthetic receptor binding with genetically engineered dimeric analyte d. Biosens. Bioelectron. 156, 112112 (2020). doi: https://doi.org/10.1016/j.bios.2020.112112

Journal version is available:

https://www.sciencedirect.com/science/article/abs/pii/S0956566320301093

protein-based drugs, or when studying the interaction of antigen with antibody in order to design more reliable immunosensors. From the point of view of mathematical modelling even the case of antigen-antibody binding is not very simple, because the antibody has two binding sites and therefore a detailed mathematical description of interaction kinetics becomes rather complex and several association and dissociation steps need to be taken into account in order to describe accurately antigen-antibody complex formation. However, until now, these issues have generally not been taken into consideration during the evaluation of antigen-antibody and other protein-protein binding due to the relatively complex calculations and some experimental limitations, which do not allow in situ evaluation of binding kinetics. But recent advances in electrochemical (Ramanavicius et al., 2014), photoluminescence and ellipsometry-based (Baleviciute et al., 2013; Balevicius et al., 2014) techniques allow us to evaluate very accurately the binding kinetics of affinity-reagents in situ. Hence, the evaluation and modelling of protein-protein binding kinetics is an important issue during: (i) the development of affinity sensors (especially immunosensors and receptor-based sensors) and (ii) the prediction of signaling protein based drug efficiency.

Therefore, in order to advance our knowledge of multi-site based binding kinetics, in this research we have applied TIRE-based in situ measurements to evaluate the binding kinetics between an immobilized bidentate-receptor and several genetically engineered bidentateligands, which differ by the kind of linker $(L 2, L 7$ and $L \alpha)$ that was used for inter-linking of GCSF proteins and are of different length and flexibility. In particular, we have investigated the binding kinetics of an immobilized bidentate GCSF receptor (GCSF-R) with three different bidentate-ligands based on homo-dimeric derivatives of GCSF: (GCSF) $)_{2} L 2,(\mathrm{GCSF})_{2} L 7$, $(\mathrm{GCSF})_{2} L \alpha$. In addition, the relation of binding kinetics with the structure of linkers, which have been applied in the design of three above-mentioned GCSF-based homo-dimeric derivatives, has been determined.

\section{Experimental}


I. Plikusiene, Z. Balevicius, A. Ramanaviciene, J. Talbot, G. Mickiene, S. Balevicius, A. Stirke, A. Tereshchenko, L. Tamosaitis, G. Zvirblis, A. Ramanavicius, Evaluation of affinity sensor response kinetics towards dimeric ligands linked with spacers of different rigidity: Immobilized recombinant granulocyte colony-stimulating factor based synthetic receptor binding with genetically engineered dimeric analyte d. Biosens. Bioelectron. 156, 112112 (2020). doi: https://doi.org/10.1016/j.bios.2020.112112

Journal version is available:

https://www.sciencedirect.com/science/article/abs/pii/S0956566320301093

\section{Chemicals}

All basic chemicals and protein-G were purchased from Sigma-Aldrich (Steinheim, Germany).

Protein fusion technology was applied to construct interacting proteins used in this research:

The three homo-dimeric derivatives GCSF derivatives $\left((\mathrm{GCSF})_{2} L \alpha\right)$, (GCSF) ${ }_{2} L 2$, and $\left.(\mathrm{GCSF})_{2} L 7\right)$ ), indicated generally as $(\mathrm{GCSF})_{2} L \mathrm{X}$, were developed and produced by Profarma UAB (Vilnius, Lithuania) according to a previously reported protocol (Mickiene et al., 2016). For this, the bacterial plasmids were constructed by genetically fused two mGCSF proteins encoding recombinant human DNA via linker DNA encoding specific peptides ( -( $\left.\mathrm{SG}_{4}\right)-\left(\mathrm{SG}_{4}\right)$ S- $(L 2),-\left(\mathrm{SG}_{4}\right)-\left(\mathrm{SG}_{4}\right)-\left(\mathrm{SG}_{4}\right)-\left(\mathrm{SG}_{4}\right)-\left(\mathrm{SG}_{4}\right)-\left(\mathrm{SG}_{4}\right)-\left(\mathrm{SG}_{4}\right)-\mathrm{S}-(L 7)$, -SGLEA-(EAAAK $)_{4}$-ALEA$(\text { EAAAK })_{4}-$ ALEGS- $(L \alpha)$ ) for the design of corresponding GCSF-dimers: $(\mathrm{GCSF})_{2} L 2$, $\left.(\mathrm{GCSF})_{2} L 7\right),(\mathrm{GCSF})_{2} L \alpha$ (Table 1).

Table 1. The structure of GCSF fusion protein dimers linked with different linkers.

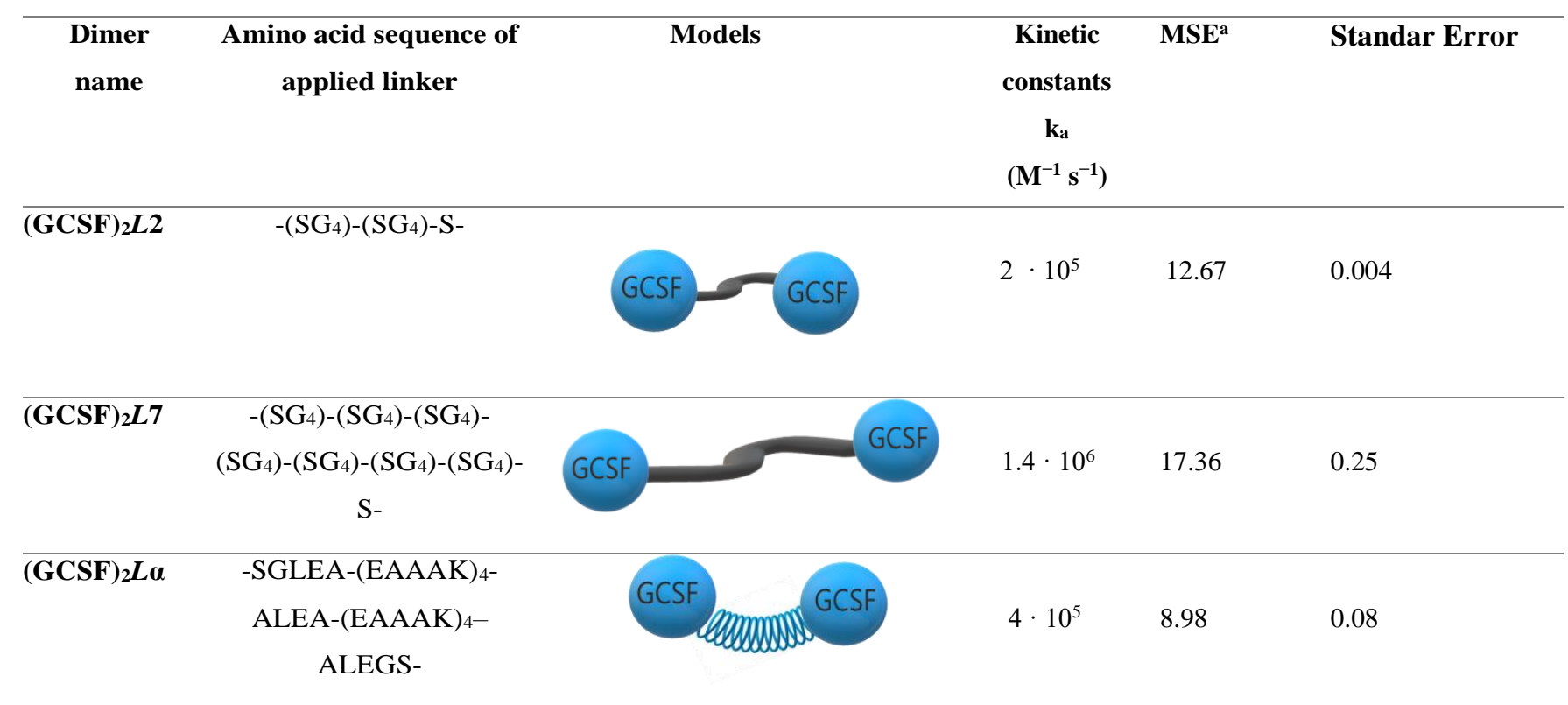

\footnotetext{
${ }^{\mathrm{a}}$ Mean Square Error for $\mathrm{F}(\mathrm{t})$ values obtained from optical model.

${ }^{\mathrm{b}}$ Standard Error obtained from fitting experimental points.
} 
I. Plikusiene, Z. Balevicius, A. Ramanaviciene, J. Talbot, G. Mickiene, S. Balevicius, A. Stirke, A. Tereshchenko, L. Tamosaitis, G. Zvirblis, A. Ramanavicius, Evaluation of affinity sensor response kinetics towards dimeric ligands linked with spacers of different rigidity: Immobilized recombinant granulocyte colony-stimulating factor based synthetic receptor binding with genetically engineered dimeric analyte d. Biosens. Bioelectron. 156, 112112 (2020). doi: https://doi.org/10.1016/j.bios.2020.112112

Journal version is available:

https://www.sciencedirect.com/science/article/abs/pii/S0956566320301093

The orientation and distance between GCSF ligands in the homo-dimeric derivative $(\mathrm{GCSF})_{2} L \alpha$ was controlled by using an alpha-helix-forming peptide linker (Arai et al., 2001). Some more details about generation, purification and biological activity of homo-dimeric ligands $(\mathrm{GCSF})_{2} L 2,(\mathrm{GCSF})_{2} L 7,(\mathrm{GCSF})_{2} L \alpha$ have been reported in earlier research (Mickiene et al., 2017). Chimeric genetically modified receptor - GCSF-R was purchased from Abcam (Cambridge, UK). All aqueous solutions were prepared in Type 1 (Ultrapure) water purified by a Direct-Q 3 ultrapure water from Merck Millipore GmbH (Darmstadt, Germany). 
I. Plikusiene, Z. Balevicius, A. Ramanaviciene, J. Talbot, G. Mickiene, S. Balevicius, A. Stirke, A. Tereshchenko, L. Tamosaitis, G. Zvirblis, A. Ramanavicius, Evaluation of affinity sensor response kinetics towards dimeric ligands linked with spacers of different rigidity: Immobilized recombinant granulocyte colony-stimulating factor based synthetic receptor binding with genetically engineered dimeric analyte d. Biosens. Bioelectron. 156, 112112 (2020). doi: https://doi.org/10.1016/j.bios.2020.112112

Journal version is available:

https://www.sciencedirect.com/science/article/abs/pii/S0956566320301093

Equipment and experimental setup for TIRE measurements

The experimental setup (Fig. 1) used for the present investigations consisted of a spectral ellipsometer M-2000X J.A.Woollam (Lincoln, USA) with rotating compensator, BK7 70 glass prism and $1 \mathrm{~mm}$ thick BK7 glass slide (BK7-glass), which was covered by $2 \mathrm{~nm}$ layer of chromium and $50 \mathrm{~nm}$ layer of gold, (BK7-glass/Cr-Au) was purchased from XanTec bioanalytics GmbH (Duesseldorf, Germany). During ellipsometry measurements, differently modified (see descriptions below) BK7-glass/Cr-Au were attached to the prism by refraction index matching fluid (Cargille, USA).

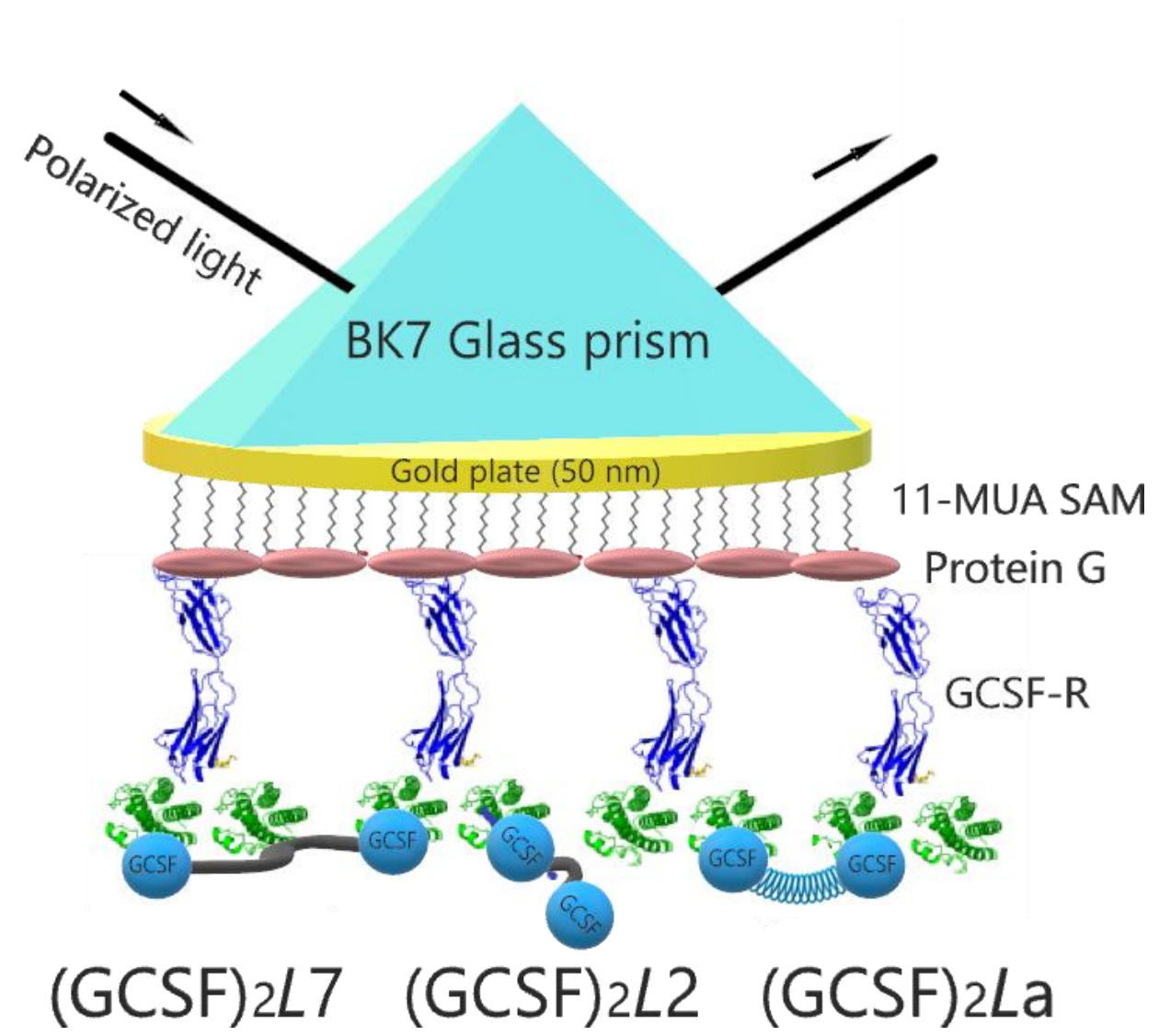

Figure 1. TIRE experimental setup for GCSF-R receptor and dimeric (GCSF) $)_{2} L X\left((\mathrm{GCSF})_{2} L \alpha\right.$, $(\mathrm{GCSF})_{2} L 2$ and $\left.\left.(\mathrm{GCSF})_{2} L 7\right)\right)$ interaction. Note: the dimensions of structural elements do not match their real sizes. 
I. Plikusiene, Z. Balevicius, A. Ramanaviciene, J. Talbot, G. Mickiene, S. Balevicius, A. Stirke, A. Tereshchenko, L. Tamosaitis, G. Zvirblis, A. Ramanavicius, Evaluation of affinity sensor response kinetics towards dimeric ligands linked with spacers of different rigidity: Immobilized recombinant granulocyte colony-stimulating factor based synthetic receptor binding with genetically engineered dimeric analyte d. Biosens. Bioelectron. 156, 112112 (2020). doi: https://doi.org/10.1016/j.bios.2020.112112

Journal version is available:

https://www.sciencedirect.com/science/article/abs/pii/S0956566320301093

The BK7-glass/Cr-Au was pretreated in piranha solution, consisting of 2/3 sulphuric acid and $1 / 3$ peroxide, for 2 minutes followed by rinsing in ethanol and later in Type 1 (Ultrapure) water. Then a self-assembled monolayer (SAM) consisting of 11-MUA was formed by immersing the pretreated BK7-glass/Cr-Au sensor chip into $1 \mathrm{mM}$ solution of 11mercaptoundecanoic acid (MUA) in ethanol for 12 hours. The formed BK7-glass/Cr-Au/MUA structure was rinsed with ethanol and Type 1 (Ultrapure) water and then dried using argon gas. Then carboxyl groups of 11-MUA were activated using the solution of $0.1 \mathrm{M} \mathrm{N}$ hydroxysuccinimide (NHS) and $0.4 \mathrm{M} \mathrm{N}$-(3-dimethylaminopropyl)-N'-ethylcarbodiimide hydrochloride (EDC). A fresh solution containing 0.1 M of NHS and 0.4 M of EDC was injected into the cell that was then incubated for 50 minutes. The cell was then rinsed with a $10 \mathrm{mM}$ sodium acetate buffer, $\mathrm{pH}$ 4.0. When a steady-state TIRE-based signal was achieved, a solution containing $100 \mu \mathrm{g} / \mathrm{ml}$ of protein-G in $10 \mathrm{mM}$ of sodium acetate buffer, $\mathrm{pH}$ 4.0, was added into the cell and after the registration of TIRE-based signal for $30 \mathrm{~min}$ BK7-glass/Cr$\mathrm{Au} / \mathrm{MUA} /$ protein-G was again rinsed with the same sodium acetate buffer, $\mathrm{pH}$ 4.0. An important task is the formation of oriented GCSF-R layer. A set of experiments was done to determine the optimal concentrations, immobilisation time, regeneration time and some others conditions necessary for the formation protein G layer. It was determined that the $100 \mu \mathrm{g} / \mathrm{ml}$ of protein-G in $10 \mathrm{mM}$ of sodium acetate buffer, $\mathrm{pH} 4.0$, is the most suitable concentration for the formation of well-packed protein $G$ layer. The next most important protein G layer formation condition is the duration of incubation in protein $\mathrm{G}$ solution. The formation kinetics of protein $\mathrm{G}$ layer on $\mathrm{BK} 7$-glass/Cr-Au/MUA structure is presented in figure 2, which illustrates that after the washing with PBS for $48 \mathrm{~min}$ the signal drop is negligible. This experiment shows that a $30 \mathrm{~min}$ incubation is sufficient for the formation of well-packed protein G layer.

The optimization of concentrations for GCSF-R 'site-directed immobilization' was established by choosing a $5 \mu \mathrm{g} / \mathrm{ml}$ solution of GCSF-R to form a densely-packed and welloriented GCSF-R layer. The resulting surface concentration $2 \times 10^{13}$ molecules $/ \mathrm{cm}^{2}$ of GCSF-R 
I. Plikusiene, Z. Balevicius, A. Ramanaviciene, J. Talbot, G. Mickiene, S. Balevicius, A. Stirke, A. Tereshchenko, L. Tamosaitis, G. Zvirblis, A. Ramanavicius, Evaluation of affinity sensor response kinetics towards dimeric ligands linked with spacers of different rigidity: Immobilized recombinant granulocyte colony-stimulating factor based synthetic receptor binding with genetically engineered dimeric analyte d. Biosens. Bioelectron. 156, 112112 (2020). doi: https://doi.org/10.1016/j.bios.2020.112112

Journal version is available:

https://www.sciencedirect.com/science/article/abs/pii/S0956566320301093

on the surface of the sensing structure is over 100 times higher than that on a living-cell surface. Therefore, $5 \mu \mathrm{g} / \mathrm{ml}$ solution of GCSF-R was applied to ensure the formation of such denselypacked GCSF-R receptor layer in BK7-glass/Cr-Au/MUA/protein-G/GCSF-R structure. Moreover, in previously reported research (Balevicius et al., 2014) we have determined that if $10 \mu \mathrm{g} / \mathrm{ml}$ concentration of bidentate homo-dimeric GCSF-based derivatives is applied then the most of immobilized GCSF-R binding sites are involved into immune-complex formation after $40 \mathrm{~min}$ lasting interaction. Therefore, this concentration $(10 \mu \mathrm{g} / \mathrm{ml})$ of bidentate homo-dimeric GCSF-based derivatives $\left((\mathrm{G}-\mathrm{CSF})_{2} L 2,(\mathrm{G}-\mathrm{CSF})_{2} L 7\right.$ or $\left.(\mathrm{G}-\mathrm{CSF})_{2} L \alpha\right)$ was applied in recent research during the investigation of interaction kinetics with immobilized GCSF-R receptor.

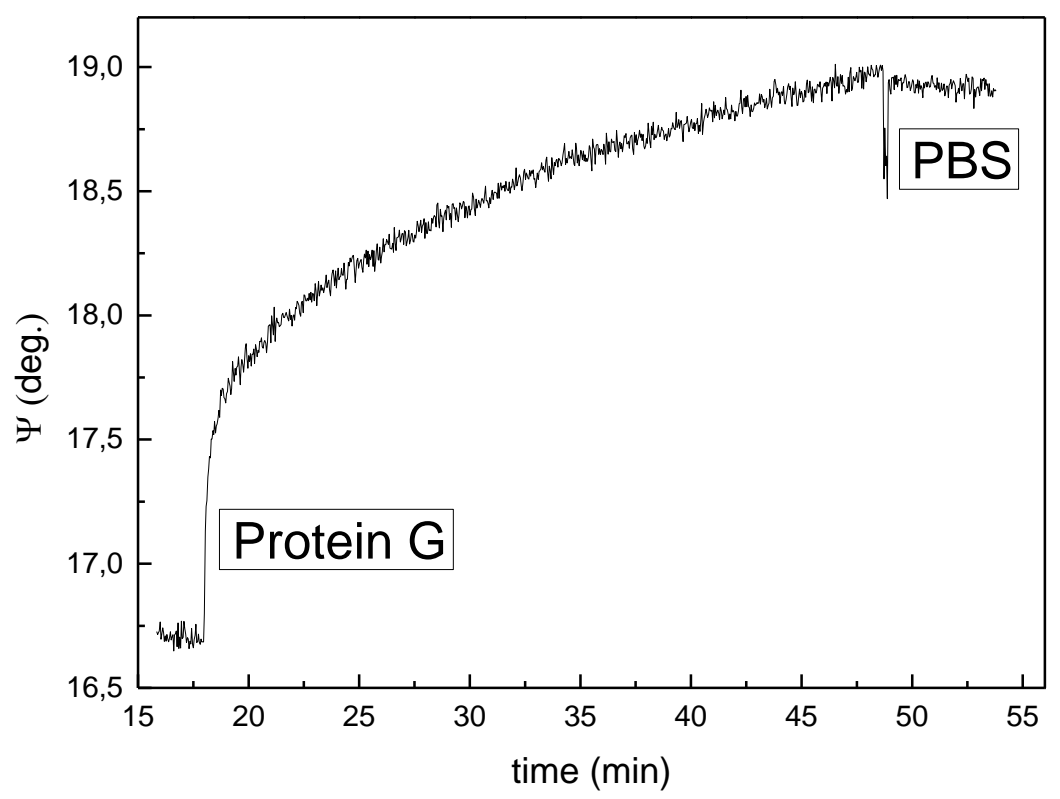

Figure 2. Immobilisation kinetics of protein G on 11-MUA SAM monitored as the evolution of ellipsometric parameter ' $\Psi$ ' in time.

To block the remaining unbound activated carboxyl groups, the SPR-disk, modified with a layer of covalently immobilized protein-G (BK7-glass/Cr-Au/MUA/protein-G), was 
I. Plikusiene, Z. Balevicius, A. Ramanaviciene, J. Talbot, G. Mickiene, S. Balevicius, A. Stirke, A. Tereshchenko, L. Tamosaitis, G. Zvirblis, A. Ramanavicius, Evaluation of affinity sensor response kinetics towards dimeric ligands linked with spacers of different rigidity: Immobilized recombinant granulocyte colony-stimulating factor based synthetic receptor binding with genetically engineered dimeric analyte d. Biosens. Bioelectron. 156, 112112 (2020). doi: https://doi.org/10.1016/j.bios.2020.112112

Journal version is available:

https://www.sciencedirect.com/science/article/abs/pii/S0956566320301093

treated with $1 \mathrm{M}$ ethanolamine hydrochloride, $\mathrm{pH} 8.5$ for $15 \mathrm{~min}$. After this, non-covalently bounded protein was removed by washing with $10 \mathrm{mM}$ solution of glycine, $\mathrm{pH} 3.0$, for $5 \mathrm{~min}$.

The layer of oriented granulocyte colony-stimulating factor receptor proteins (GCSF$\mathrm{R}$ ), which specifically bind to protein-G via the Fc subunit of the GCSF-R were purchased from Chimera, Abcam, Cambridge, UK. The receptor GCSF-R was immobilized by the formation of protein-G/GCSF-R complex on the surface of initially prepared BK7-glass/Cr$\mathrm{Au} / \mathrm{MUA} /$ protein-G structure and in this way an advanced structure (BK7-glass/Cr-Au /MUA/protein-G/HSA\&GCSF-R), which was sensitive to GCSF-based dimers, was formed. During the formation of GCSF-R-based layer the solution containing $5(\mathrm{~g} / \mathrm{ml}$ of GCSF-R was injected into the TIRE-cell filled with $10 \mathrm{mM}$ potassium phosphate buffer, $\mathrm{pH}$ 7.4, containing $140 \mathrm{mM}$ of $\mathrm{NaCl}, 2,7 \mathrm{mM}$ of $\mathrm{KCl}$ (PBS buffer), and then BK7-glass/Cr-Au/MUA structure was incubated in this solution for $40 \mathrm{~min}$. The BK7-glass/Cr-Au/MUA/proteinG/HSA\&GCSF-R structure was generated by immobilizing protein-G and GCSF-R proteins, followed by rinsing in the same $10 \mathrm{mM}$ PBS buffer, $\mathrm{pH}$ 7.4.

Interaction kinetics of BK7-glass/Cr-Au/MUA/protein-G/HSA\&GCSF-R with three different homo-dimeric GCSF-derivatives $\left((\mathrm{GCSF})_{2} L \alpha,(\mathrm{GCSF})_{2} L 2\right.$ and $\left.\left.(\mathrm{GCSF})_{2} L 7\right)\right)$, which were designed especially for this experiment, was evaluated in PBS buffer, $\mathrm{pH}$ 7.4. For these measurements $10 \mu \mathrm{g} / \mathrm{ml}$ of each derivative $\left((\mathrm{G}-\mathrm{CSF})_{2} L 2,(\mathrm{G}-\mathrm{CSF})_{2} L 7\right.$ or $\left.(\mathrm{G}-\mathrm{CSF})_{2} L \alpha\right)$ were added into the ellipsometry measurement cell. The regeneration of BK7-glass/Cr$\mathrm{Au} / \mathrm{MUA} /$ protein-G/HSA\&G-CSF- $R$ structure back into BK7-glass/Cr-Au/MUA/protein-G was performed by the incubation in $10 \mathrm{mM}$ solution of glycine, $\mathrm{pH} 3.0$, for $5 \mathrm{~min}$. Ellipsometric spectra during the formation of each molecular layer of BK7-glass/Cr-Au/MUA/proteinG/HSA\&GCSF-R structure and interaction of this structure with all three different homodimeric GCSF-derivatives $\left((\mathrm{GCSF})_{2} L \alpha,(\mathrm{GCSF})_{2} L 2\right.$ and $\left.\left.(\mathrm{GCSF})_{2} L 7\right)\right)$ were evaluated. The TIRE data were analysed using a multi-layer optical model (Mitchell et al., 2016). In this study, the multi-layer model applied for the evaluation of ellipsometry results represented the following structure: (BK7-glass/Cr-Au/MUA/Protein-G/HSA\&GCSF-R/(PBS solution). The optical response of $\mathrm{Cr}$-Au layers deposited on the glass plate connected with glass prism via 
I. Plikusiene, Z. Balevicius, A. Ramanaviciene, J. Talbot, G. Mickiene, S. Balevicius, A. Stirke, A. Tereshchenko, L. Tamosaitis, G. Zvirblis, A. Ramanavicius, Evaluation of affinity sensor response kinetics towards dimeric ligands linked with spacers of different rigidity: Immobilized recombinant granulocyte colony-stimulating factor based synthetic receptor binding with genetically engineered dimeric analyte d. Biosens. Bioelectron. 156, 112112 (2020). doi: https://doi.org/10.1016/j.bios.2020.112112

Journal version is available:

https://www.sciencedirect.com/science/article/abs/pii/S0956566320301093

refractive index matching liquid was measured in the cell filled with PBS, pH 7.4. The applied multilayer model in addition to ellipsometric data takes into account the morphology data of the thickness and surface roughness of gold layer (Tamada et al., 2006). Thus, the spectra of optical constants of Au layer were determined and subsequently used in a model as fixed parameters. After the formation of self-assembled monomolecular MUR-11 monolayer on the gold-based substrate, the newly formed BK7-glass/Cr-Au/MUA structure was evaluated by optical ellipsometry and optical constants of MUR-11 monolayer were determined from the evaluation of this multilayer system. After this MUR-11's carboxylic groups activated by subsequent treatment with EDC and NHS solutions were covalently modified by protein-G layer that was also followed by TIRE. Then the solution containing dissolved bidentate GCSF receptor (GCSF-R) was added and it formed complex with protein-G. In this way a welloriented layer of GCSF-R receptor was formed on glass/Cr-Au/MUA/protein-G surface which resulted in a new - BK7-glass/Cr-Au/MUA/protein-G/HSA\&GCSF-R structure. The detailed experimental protocol, which describes all the above-mentioned immobilization steps, has been presented previously (Balevicius et al., 2019). Finally, the BK7-glass/Cr$\mathrm{Au} / \mathrm{MUA} /$ protein-G/HSA\&GCSF-R structure was washed by buffer and used in TIRE-based sensor design. The sensor was tested in the presence of the same concentration $2.6 \cdot 10^{-7} \mathrm{M}$ of all three GCSF based bidentate homo-dimeric derivatives $\left((\mathrm{GCSF})_{2} L 2,(\mathrm{GCSF})_{2} L 7\right.$ and $\left.(\mathrm{GCSF})_{2} L \alpha\right)$. Note, when referring to common properties of all three derivatives they will be abbreviated as $(\mathrm{GCSF})_{2} L X$; when refering to $\left((\mathrm{GCSF})_{2} L 7\right.$ and $\left.(\mathrm{GCSF})_{2} L \alpha\right)$, which have a long linker, they will be abbreviated as $(\mathrm{GCSF})_{2} L X^{*}$.

All the above mentioned sensing layer development and analyte determination procedures performed in ellipsometry cell and TIRE spectra were recorded during all the surface-modification steps. Optical constants, which were determined for each layer, were kept fixed during the regression analysis of ellipsometry data obtained during the evaluation of multilayered structure after the formation of the next layer formed on the top of before evaluated multilayered structure. The experimental protocol, which describes all abovementioned immobilization steps, is illustrated in figure 3. 
I. Plikusiene, Z. Balevicius, A. Ramanaviciene, J. Talbot, G. Mickiene, S. Balevicius, A. Stirke, A. Tereshchenko, L. Tamosaitis, G. Zvirblis, A. Ramanavicius, Evaluation of affinity sensor response kinetics towards dimeric ligands linked with spacers of different rigidity: Immobilized recombinant granulocyte colony-stimulating factor based synthetic receptor binding with genetically engineered dimeric analyte d. Biosens. Bioelectron. 156, 112112 (2020). doi: https://doi.org/10.1016/j.bios.2020.112112

Journal version is available:

https://www.sciencedirect.com/science/article/abs/pii/S0956566320301093

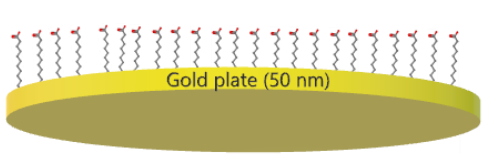

11-MUA SAM
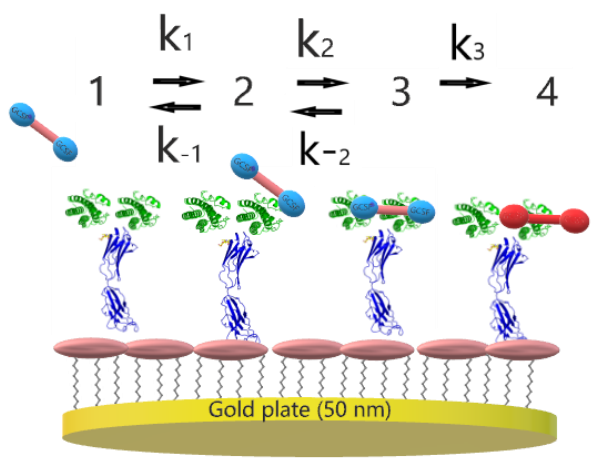

11-MUA SAM + ProtG + GCSF-R + (GCSF) 2 LX

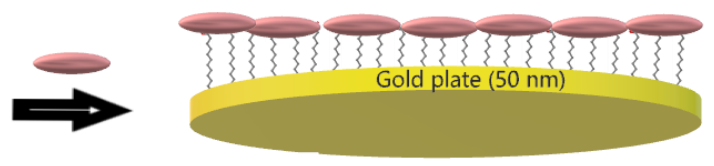

11-MUA SAM + ProtG
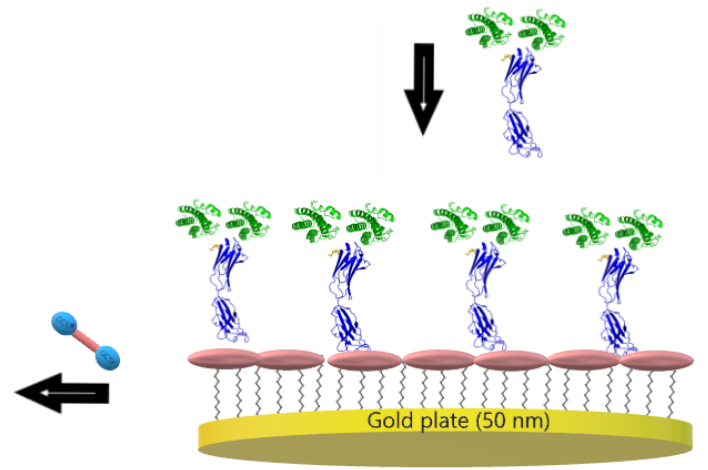

11-MUA SAM + ProtG + GCSF-R

Figure 3. Schematic representation of surface modification using various GCSF dimeric proteins. 
I. Plikusiene, Z. Balevicius, A. Ramanaviciene, J. Talbot, G. Mickiene, S. Balevicius, A. Stirke, A. Tereshchenko, L. Tamosaitis, G. Zvirblis, A. Ramanavicius, Evaluation of affinity sensor response kinetics towards dimeric ligands linked with spacers of different rigidity: Immobilized recombinant granulocyte colony-stimulating factor based synthetic receptor binding with genetically engineered dimeric analyte d. Biosens. Bioelectron. 156, 112112 (2020). doi: https://doi.org/10.1016/j.bios.2020.112112

Journal version is available:

https://www.sciencedirect.com/science/article/abs/pii/S0956566320301093

Kinetic analysis of the association of $(G C S F)_{2} L 2,(G C S F)_{2} L 7$ and $(G C S F)_{2} L \alpha$ with immobilized GCSF-R receptor

Experimental ellipsometric data showed that after the treatment with bare buffer only a fraction of $(\mathrm{GCSF})_{2} \mathrm{LX}$ proteins dissociated from BK7-glass/Cr-Au/MUA/protein-G/ HSA\&GCSF-R irreversible stage of immobilized surface (Fig. 5). Therefore, the model, which takes into account the transformation of the $(\mathrm{GCSF}-\mathrm{R})_{2}=(\mathrm{GCSF})_{2} L X^{*}$ complex into a non-dissociable one (GCSF-R)//(GCSF) $)_{2} L X^{*}$ has been applied.

It should be noted that the linkers $(L 2, L 7$ and $L \alpha)$ are very different in length and flexibility, which affects the ability of both GCSF ligands to interact with each other. The various linkers $(L 2, L 7$ and $L \alpha)$, which bind two GCSF subunits in the structures of (GCSF) $2 L X$ proteins result in different binding kinetics, in different ways: $(\mathrm{GCSF})_{2} L 2$, obeys the standard Langmuir equation (Eq. 1). This is because $L 2$ is short ligand and so it prevents the second GCSF ligand from finding a binding partner if the first is already complexed with GCSF-R receptor. To describe the binding kinetics of both $(\mathrm{GCSF})_{2} L 7$ and (GCSF) $2 L \alpha$, however, the advanced model, which was previously described and evaluated in our previous research (Balevicius et al., 2018) is required. This is because $L 7$ and $L \alpha$ are much longer ligands than $L 2$, therefore, after the binding of the first GCSF ligand the long spacers $L 7$ and $L \alpha$ enable the second GCSF ligand to bind to a free GCSF-R receptor. The difference in the flexibility of spacers $L 7$ and $L \alpha$ is related to their difference in structure: spacer $L 7$ is more flexible than $L \alpha$ because the latter is based on $\alpha$-spiral, which is relatively rigid, while spacer $L 7$ is based on polypeptide, which does not form an $\alpha$-spiral is therefore flexible and the GCSF ligands have more freedom to move freely in comparison to $(\mathrm{GCSF})_{2} L 7$. The fill factor $(F)$, which was applied for the estimation of binding efficiency, is the normalized refractive index, which is calculated using regression analysis of experimental curves ' $\Psi$ ' and ' $\Delta$ ' vs time by fitting experimental and theoretically calculated curves. These parameters were used as an/the analytical signal in the experimental setup. The clear change of fill factor $(F)$ vs time close to the saturation of Ellipsometry-based signal after about $3 \mathrm{~s}$ is evident from the binding kinetics. 
I. Plikusiene, Z. Balevicius, A. Ramanaviciene, J. Talbot, G. Mickiene, S. Balevicius, A. Stirke, A. Tereshchenko, L. Tamosaitis, G. Zvirblis, A. Ramanavicius, Evaluation of affinity sensor response kinetics towards dimeric ligands linked with spacers of different rigidity: Immobilized recombinant granulocyte colony-stimulating factor based synthetic receptor binding with genetically engineered dimeric analyte d. Biosens. Bioelectron. 156, 112112 (2020). doi: https://doi.org/10.1016/j.bios.2020.112112

Journal version is available:

https://www.sciencedirect.com/science/article/abs/pii/S0956566320301093

Since the L $\alpha$ ligand (in $(\mathrm{GCSF})_{2} L \alpha$ ) is rigid we observe a change in the fill factor $(F)$ vs time, which approaches saturation within $20 \mathrm{~s}$, which is about 6 times slower than in the case of $(\mathrm{GCSF})_{2} L 7$ where GCSF ligands are connected by an $L 7$ linker. This means that the association of (GCSF) ${ }_{2} L 7$ on BK7-glass/Cr-Au/MUA/protein-G/ HSA\&GCSF-R is faster and association constant ka presented in Table 1 is two times higher than that determined for the interaction of monomeric GCSF (mGCSF) with BK7-glass/Cr-Au/MUA/protein-G/HSA\&GCSF-R structure (Balevicius et al., 2019).

This effect can be related to the increased affinity of $(\mathrm{GCSF})_{2} L 7$ towards the GCSF-Rmodified surface. Because the presence of two GCSF ligands linked with very flexible linker - L7 - significantly increases the probability of association of (GCSF) ${ }_{2} L 7$ in comparison to other GCSF monomeric or dimeric derivatives. Thus, the results presented here show that ellipsometry-based measurements of binding kinetics are suitable for the determination of the binding mechanism of two receptor sites having receptors or antibodies, which also have two sites accessible for ligand binding, with double sided ligands. 
I. Plikusiene, Z. Balevicius, A. Ramanaviciene, J. Talbot, G. Mickiene, S. Balevicius, A. Stirke, A. Tereshchenko, L. Tamosaitis, G. Zvirblis, A. Ramanavicius, Evaluation of affinity sensor response kinetics towards dimeric ligands linked with spacers of different rigidity: Immobilized recombinant granulocyte colony-stimulating factor based synthetic receptor binding with genetically engineered dimeric analyte d. Biosens. Bioelectron. 156, 112112 (2020). doi: https://doi.org/10.1016/j.bios.2020.112112

Journal version is available:

https://www.sciencedirect.com/science/article/abs/pii/S0956566320301093

$\mathrm{GCSF}-\mathrm{R}+(\mathrm{GCSF})_{2} \mathrm{~L} 2(\mathrm{GCSF}-\mathrm{R})-(\mathrm{GCSF})_{2} L \mathrm{X}$

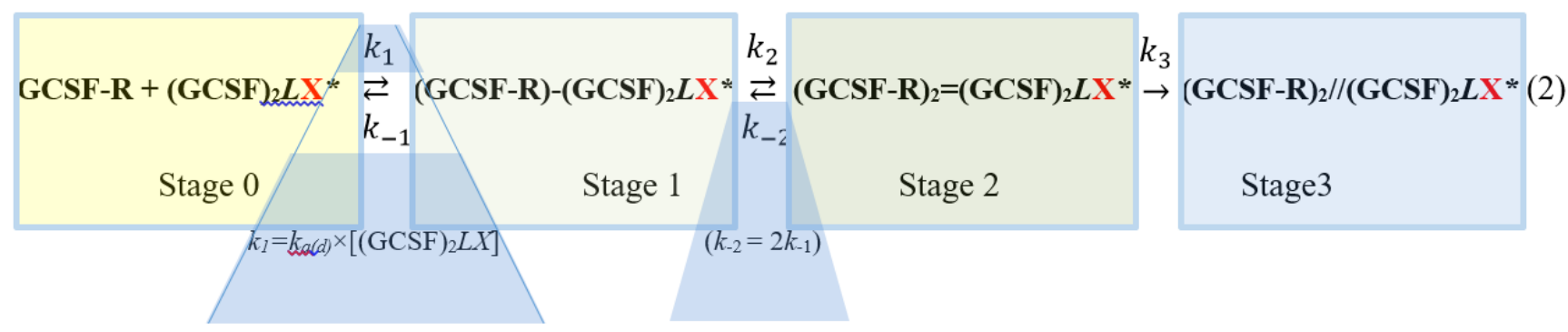

Where:

GCSF-R is the immobilized GCSF-Receptor;

$(\mathrm{GCSF})_{2} L X^{*}$ is a freely diffusing GCSF dimer $(\mathrm{GCSF})_{2} L 7$ or $(\mathrm{GCSF})_{2} L \alpha$;

$(\mathrm{GCSF}-\mathrm{R})-(\mathrm{GCSF})_{2} L \mathrm{X}^{*}$ is a complex of $(\mathrm{GCSF})_{2} L X^{*}$ with single GCSF-R receptor;

$(\mathrm{GCSF}-\mathrm{R})_{2}=(\mathrm{GCSF})_{2} L \mathrm{X}^{*}$ is a complex of $(\mathrm{GCSF})_{2} L X^{*}$ with two GCSF-R receptors;

$(\mathrm{GCSF}-\mathrm{R})_{2} / /(\mathrm{GCSF})_{2} \mathrm{LX}^{*}$ is a complex of $(\mathrm{GCSF})_{2} L X^{*}$ with two GCSF-R receptors;

after the rearrangement of the $(\mathrm{GCSF}-\mathrm{R})_{2}=(\mathrm{GCSF})_{2} L X^{*}$ complex into a non-dissociable one $\left((\mathrm{GCSF}-\mathrm{R})_{2} / /(\mathrm{GCSF})_{2} L \mathrm{X}^{*}\right)$;

$\mathrm{k}_{\mathrm{a}(\mathrm{d})}$ - second order association rate constant, which characterizes the first step of association of GCSF- Receptors with (GCSF) ${ }_{2} L X^{*}$ and the formation of the (GCSF-R)-(GCSF) ${ }_{2} L X^{*}$ complex;

$\mathrm{k}_{1}$ - pseudo-first order association rate constant $\left(\mathrm{k}_{1}=\mathrm{k}_{\mathrm{a}(\mathrm{d})} \times\left[(\mathrm{GCSF})_{2} L X^{*}\right]\right.$; where $\mathrm{k}_{\mathrm{a}(\mathrm{d})}$ is the above mentioned second order association rate constant and $\left[(\mathrm{GCSF})_{2} L X^{*}\right]$ is the $(\mathrm{GCSF})_{2} L X^{*}$ concentration in solution;

$\mathrm{k}_{2}$ - first order association rate constant for the association of a second GCSF ligand of (GCSF$\mathrm{R})-(\mathrm{GCSF})_{2} L X^{*}$ complex with a second free GCSF-R receptor, which results in the formation of $(\mathrm{GCSF}-\mathrm{R})_{2}=(\mathrm{GCSF})_{2} L \mathrm{X}^{*}$ complex;

$\mathrm{k}_{3}$ - first order rearrangement rate constant for the rearrangement of dissociable (GCSF-

$\mathrm{R})_{2}=(\mathrm{GCSF})_{2} L X^{*}$ complex into non-dissociable $(\mathrm{GCSF}-\mathrm{R})_{2} / /(\mathrm{GCSF})_{2} L X^{*}$ complex;

$\mathrm{k}_{-1}$ - first order dissociation rate constant for the dissociation of (GCSF-R)-(GCSF) ${ }_{2} L X^{*}$ complex; 
I. Plikusiene, Z. Balevicius, A. Ramanaviciene, J. Talbot, G. Mickiene, S. Balevicius, A. Stirke, A. Tereshchenko, L. Tamosaitis, G. Zvirblis, A. Ramanavicius, Evaluation of affinity sensor response kinetics towards dimeric ligands linked with spacers of different rigidity: Immobilized recombinant granulocyte colony-stimulating factor based synthetic receptor binding with genetically engineered dimeric analyte d. Biosens. Bioelectron. 156, 112112 (2020). doi: https://doi.org/10.1016/j.bios.2020.112112

Journal version is available:

https://www.sciencedirect.com/science/article/abs/pii/S0956566320301093

$\mathrm{k}_{-2}$ - first order dissociation rate constant for the partial dissociation of (GCSF$\mathrm{R}) 2=(\mathrm{GCSF}) 2 L X^{*}$ complexes $\left(\mathrm{k}_{-2}=2 \mathrm{k}_{-1}\right)$.

It should be noted that the ligand concentration significantly exceeded the immobilized GCSF-R receptor concentration; therefore, only the surface concentration of the $(\mathrm{GCSF})_{2} L X^{*}$, which was involved in the formation of $(\mathrm{GCSF}-\mathrm{R})-(\mathrm{GCSF})_{2} L \mathrm{X}^{*},(\mathrm{GCSF}-\mathrm{R})_{2}=(\mathrm{GCSF})_{2} L \mathrm{X}^{*}$ and (GCSF-R $)_{2} / /(\mathrm{GCSF})_{2} L X^{*}$ complexes, was taken into consideration in the calculations of association/dissociation/rearrangement kinetics, using equation 2 .

This kinetic model is described by the following system of differential equations:

$\frac{d \rho_{1}}{d t}=k_{1}\left(1-\rho_{1}-\rho_{2}-\rho_{3}\right)-\left(k_{-1}+k_{2}\right) \rho_{1}+k_{-2} \rho_{2}$

$\frac{d \rho_{2}}{d t}=k_{2} \rho_{1}-\left(k_{-2}+k_{3}\right) \rho_{2}$

$\frac{d \rho_{3}}{d t}=k_{3} \rho_{2}$

$k_{-2}=2 k_{-1}$

where:

$\rho_{1}$ is the fraction of GCSF-R to which $(\mathrm{GCSF})_{2} L X^{*}$ can be bounded via one ligand during the formation of (GCSF-R)-(GCSF) $)_{2} L X^{*}$ complex;

$\rho_{2}$ is the fraction of GCSF-R to which $(\mathrm{GCSF})_{2} L X^{*}$ is bounded via two ligands during the formation of $(\mathrm{GCSF}-\mathrm{R})_{2}=(\mathrm{GCSF})_{2} L X^{*}$ complex;

$\rho_{3}$ is the fraction of GCSF-R to which (GCSF) ${ }_{2} L X^{*}$ is bounded when non-dissociable (GCSF$\mathrm{R})_{2} / /(\mathrm{GCSF})_{2} L X^{*}$ complex is formed. 
I. Plikusiene, Z. Balevicius, A. Ramanaviciene, J. Talbot, G. Mickiene, S. Balevicius, A. Stirke, A. Tereshchenko, L. Tamosaitis, G. Zvirblis, A. Ramanavicius, Evaluation of affinity sensor response kinetics towards dimeric ligands linked with spacers of different rigidity: Immobilized recombinant granulocyte colony-stimulating factor based synthetic receptor binding with genetically engineered dimeric analyte d. Biosens. Bioelectron. 156, 112112 (2020). doi: https://doi.org/10.1016/j.bios.2020.112112

Journal version is available:

https://www.sciencedirect.com/science/article/abs/pii/S0956566320301093

It is important to note that the total number of GCSF-R receptors available for the $(\mathrm{GCSF})_{2} L X^{*}$ is equal to the maximal number of (GCSF) ${ }_{2} L X^{*}$ molecules, which can bind to Bk7-glass/Cr-Au/MUA/Protein-G/HSA\&GCSF-R slide surface via both GCSF ligands of $(\mathrm{GCSF})_{2} L X^{*}$ molecule. The boundary conditions, which were applied to start numerical calculations were $\rho 1(0)=\rho 2(0)=\rho 3(0)=0$. (Balevicius et al., 2019).

The two types of dimer (GCSF) $)_{2} L X^{*}$ molecules, which are linked by linkers ( $L 2$ and L7) of the same structure but of different polypeptide chain length, exhibit different capabilities to bind to immobilized receptor - GCSF-R. (GCSF) $)_{2} L 2$ molecules in which GCSF ligands are connected by shorter $L 2$ linker have a lower probability to associate with the two GCSF-R receptor sites via both GCSF ligands, because due to short length of $L 2$ the distance between GCSF ligands is significantly shorter than the average distance between immobilized GCSF-R receptor sites. For this reason, in this case the kinetics of (GCSF-R)-(GCSF) $)_{2} L 2$ complex formation is well described by the standard Langmuir equation, which is parametrised by only two constants (i.e. association $\left(\mathrm{k}_{\mathrm{a}}\right)$ and dissociation $\left(\mathrm{k}_{\mathrm{d}}\right)$ ) and does not take into account the second phase of ligand binding. On the contrary for dimers (GCSF) ${ }_{2} L 7$ and (GCSF) ${ }_{2} L \alpha$ (which in general equations and explanations are indicated as $\left.(\mathrm{GCSF})_{2} L X^{*}\right)$ having linkers $(L 7, L \alpha)$, which are such long that both GCSF ligands are able to reach immobilized receptor sites. In these two cases, the formation of $(\mathrm{GCSF}-\mathrm{R})_{2}=(\mathrm{GCSF})_{2} L 7$ and $(\mathrm{GCSF}-\mathrm{R})_{2}=(\mathrm{GCSF})_{2} L \alpha$ complexes is more complicated, because after the binding of both GCSF ligands the rearrangement of formed complexes $(\mathrm{GCSF}-\mathrm{R})_{2}=(\mathrm{GCSF})_{2} L 7$ and $(\mathrm{GCSF}-\mathrm{R})_{2}=(\mathrm{GCSF})_{2} L \alpha$ takes place, which due to rearrangement of binding sites transforms into non-dissociable complexes (GCSF-R $)_{2} / /(\mathrm{GCSF})_{2} L 7$ and $(\mathrm{GCSF}-\mathrm{R})_{2} / /(\mathrm{GCSF})_{2} L \alpha$.

It should be noted that all three homo-dimeric derivatives $\left((\mathrm{GCSF})_{2} L 2,(\mathrm{GCSF})_{2} L 7\right.$ and $\left.(\mathrm{GCSF})_{2} L \alpha\right)$ have different binding-kinetic constants during the above mentioned multi-step binding process (Fig. 2) due to the different linkers ( $L 2, L 7$ and $L \alpha)$ ) linking GCSF ligands. Due to the short linker $L 2$, which after binding of one GCSF unit to immobilized GCSF-R does not provide sufficient freedom for second GCSF unit to reach another GCSF-R binding-site, 
I. Plikusiene, Z. Balevicius, A. Ramanaviciene, J. Talbot, G. Mickiene, S. Balevicius, A. Stirke, A. Tereshchenko, L. Tamosaitis, G. Zvirblis, A. Ramanavicius, Evaluation of affinity sensor response kinetics towards dimeric ligands linked with spacers of different rigidity: Immobilized recombinant granulocyte colony-stimulating factor based synthetic receptor binding with genetically engineered dimeric analyte d. Biosens. Bioelectron. 156, 112112 (2020). doi: https://doi.org/10.1016/j.bios.2020.112112

Journal version is available:

https://www.sciencedirect.com/science/article/abs/pii/S0956566320301093

the binding of $(\mathrm{GCSF})_{2} \mathrm{~L} 2$ similar to the case of monomeric GCSF binding (Baleviciute et al., 2013, Balevicius et al., 2019). Therefore, to analyze the (GCSF) $)_{2} L 2$ binding kinetics it is also sufficient to apply the standard Langmuir equation (Eq. 1) (Talbot 1996). Meanwhile for the dimeric GCSF derivatives $\left((\mathrm{GCSF})_{2} L 7\right.$ and $\left.(\mathrm{GCSF})_{2} L \alpha\right)$ the consecutive association kinetics model (Eq. 2) (Balevicius et al., 2019) is more suitable. As can be seen from the evaluation of the ellipsometric parameter - ' $\Delta$ ', the dissociation phases (GCSF-R)-(GCSF) $)_{2} L 2$, (GCSF-R)$(\mathrm{GCSF})_{2} L 7$ and (GCSF-R)-(GCSF) $)_{2} L \alpha$ complexes are very different (Fig. 5).

Kinetic analysis of the binding of GCSF-based derivatives with immobilized GCSF-R receptor was performed using spectroscopic total internal reflection ellipsometry (TIRE) in its dynamic data acquisition mode. The results of the experiments are represented in Table 1 . The analysis of dynamic TIRE data of the interaction of $(\mathrm{GCSF})_{2} L 2,(\mathrm{GCSF})_{2} L 7$ or $(\mathrm{GCSF})_{2} L \alpha$ with immobilized GCSF-R has been performed by a reverse dynamic fitting procedure, which started from the values obtained for completely formed of BK7-glass/Cr-Au/MUA/proteinG/GCSF-R/(GCSF) $)_{2} L X$ structures. From the regression analysis of in situ registered data, the value of the effective refractive index was found to lie in between that of BK7-glass/Cr$\mathrm{Au} / \mathrm{MUA} /$ protein-G/HSA\&GCSF-R incubated in PBS solution and in solution maximally saturated with $(\mathrm{GCSF})_{2} L X$, solutions. Thus, the change of effective refractive index over time was transformed into the change of fill factor $(F)$, which indicated the saturation of GCSF proteins layer of BK7-glass/Cr-Au/MUA/protein-G/HSA\&GCSF-R structure by $(\mathrm{GCSF})_{2} L 2$, $(\mathrm{GCSF})_{2} L 7$ or $(\mathrm{GCSF})_{2} L \alpha$ ligands. It should be emphasized that we have assumed that the intrinsic refractive indices of GCSF-R and all three interacting derivatives $(\mathrm{GCSF})_{2} L 2$, $(\mathrm{GCSF})_{2} L 7$ or $(\mathrm{GCSF})_{2} L \alpha$ are the same, because they all are proteins and their optical properties are described using the Cauchy dispersion function. This estimation allows us to analyze the variation of effective refractive indexes of layers composed of proteins with different structures.

The consecutive association kinetics model, which we have used in this study, describes non-equilibrium process. Therefore, during the evaluation of the binding kinetics between GCSF-based derivatives and immobilized GCSF-R receptor particular attention was paid to 
I. Plikusiene, Z. Balevicius, A. Ramanaviciene, J. Talbot, G. Mickiene, S. Balevicius, A. Stirke, A. Tereshchenko, L. Tamosaitis, G. Zvirblis, A. Ramanavicius, Evaluation of affinity sensor response kinetics towards dimeric ligands linked with spacers of different rigidity: Immobilized recombinant granulocyte colony-stimulating factor based synthetic receptor binding with genetically engineered dimeric analyte d. Biosens. Bioelectron. 156, 112112 (2020). doi: https://doi.org/10.1016/j.bios.2020.112112

Journal version is available:

https://www.sciencedirect.com/science/article/abs/pii/S0956566320301093

the irreversible and, at the same time, the slowest, rate limiting step, which is characteristic for complex formation between immobilized GCSF-R receptor and dimeric GCSF ligands $\left((\mathrm{GCSF})_{2} L \alpha\right.$ and $\left.\left.(\mathrm{GCSF})_{2} L 7\right)\right)$. The latter are superior for the binding with GCSF-R receptor in the comparison to $(\mathrm{GCSF})_{2} L 2$ ligand, where GCSF ligands are bonded by short linker $-L 2$. The regression analysis of multi-layer optical model and further evaluation of the mass of GCSF-based derivatives, which are bonded to the immobilized GCSF-R, shows that homodimeric derivatives $(\mathrm{GCSF})_{2} L \alpha$ and $(\mathrm{GCSF})_{2} L 7$ bind to the receptor at a ratio of $1: 1$, while the homo-dimeric derivative $(\mathrm{GCSF})_{2} L 2$ binds at a ratio of 1:2.

Since the purification of homo-dimeric derivatives (GCSF) $)_{2} L 2$ and $(\mathrm{GCSF})_{2} L 7$ is rather difficult (Mickiene et al., 2017), the (GCSF) $)_{2} L \alpha$ homo-dimeric derivative for pharmacokinetics/pharmacodynamics trials. It is likely that the homo-dimeric derivative $(\mathrm{GCSF})_{2} \mathrm{~L} \alpha$ possesses optimal dimensions for its target receptor and the L $\alpha$ linker, which forms an alpha-helix, allows some additional conformational freedom, which makes it easier for the second GCSF-unit to orient properly towards free GCSF-R receptor, when the first GCSF-unit is already attached to the receptor (Scholz et al., 2009).

\section{Results and discussion}

The Cauchy dispersion function (Balevicius et al., 2014) was used to describe the formation of all protein layers during the development of multilayered sensor structure based on BK7glass/Cr-Au/MUA/protein-G/HSA\&GCSF-R. Calculations (data not presented) show that all theoretically available initial geometrical area of BK7-glass/Cr-Au/MUA/protein-G was covered by GCSF-R. Estimated surface area (covered by GCSF-R), which is available for the binding of $(\mathrm{GCSF})_{2} L X$ was calculated . This sensing area was estimated to be $2 \cdot 10^{12}$ GCSF$\mathrm{R} / \mathrm{cm}^{2}$. We therefore used a $5 \mu \mathrm{g} / \mathrm{ml}$ concentration of GCSF-R to ensure that all sensing surface area was covered with well-packed GCSF-R molecules. This concentration assures that TIRE cell is infused with 100 times higher the number of GCSF-R molecules that can be covalently immobilised on BK7-glass/Cr-Au/MUA/protein-G. The next step in this investigation was the evaluation of BK7-glass/Cr-Au/MUA/protein-G/HSA\&GCSF-R-based sensor action kinetics 
I. Plikusiene, Z. Balevicius, A. Ramanaviciene, J. Talbot, G. Mickiene, S. Balevicius, A. Stirke, A. Tereshchenko, L. Tamosaitis, G. Zvirblis, A. Ramanavicius, Evaluation of affinity sensor response kinetics towards dimeric ligands linked with spacers of different rigidity: Immobilized recombinant granulocyte colony-stimulating factor based synthetic receptor binding with genetically engineered dimeric analyte d. Biosens. Bioelectron. 156, 112112 (2020). doi: https://doi.org/10.1016/j.bios.2020.112112

Journal version is available:

https://www.sciencedirect.com/science/article/abs/pii/S0956566320301093

in the presence of the same concentrations of different analytes $(\mathrm{GCSF})_{2} L \alpha,(\mathrm{GCSF})_{2} L 2$, $(\mathrm{GCSF})_{2} L 7$, which all act as ligands for the immobilized receptor (GCSF-R). The results are presented in figure 4, respectively. As noted above the interaction/association of $(\mathrm{GCSF})_{2} L 2$, $(\mathrm{GCSF})_{2} L 7$ and $(\mathrm{GCSF})_{2} L \alpha$ with immobilized GCSF-R receptor is a multi-step process (Fig. 2). Therefore, the evolution of ellipsometric parameters in time was analyzed using mathematical models that consider the most important processes during the association of $(\mathrm{GCSF})_{2} L 2,(\mathrm{GCSF})_{2} L 7$ or $(\mathrm{GCSF})_{2} L \alpha$ with immobilized GCSF-R receptor. Figure 4 shows how $(\mathrm{GCSF})_{2} L \alpha,(\mathrm{GCSF})_{2} L 2$, and $(\mathrm{GCSF})_{2} L 7$ interact with the receptor site of BK7-glass/CrAu/MUA/protein-G/HSA\&GCSF-R structure respectively. Squares (curve 1), dots (curve 2) and triangles (curve 3) correspond to experimental point of interaction kinetics between immobilized GCSF-R and (GCSF) ${ }_{2} L \alpha,(\mathrm{GCSF})_{2} L 7,(\mathrm{GCSF})_{2} L 2$ respectively (Fig. 4). Curve 1 shows fitting results for GCSF-R and (GCSF) $2 L \alpha$ complex formation, curve 3 - for GCSF-R and (GCSF) $)_{2} L 7$, curve 2 - for GCSF-R and (GCSF) $)_{2} L 2$ (Fig. 4). The dynamics of the fill factor $(F)$, which was evaluated as analytical signal and represents the interaction kinetics of $(\mathrm{GCSF})_{2} L 2,(\mathrm{GCSF})_{2} L 7$ or $(\mathrm{GCSF})_{2} L \alpha$ with immobilized GCSF-R of BK7-glass/Cr-Au /MUA/protein-G/HSA\&GCSF-R structure is shown in figure 4 at $2.6 \cdot 10^{-7} \mathrm{M}$ concentrations of these compounds (GCSF) $)_{2} L 2,(\mathrm{GCSF})_{2} L 7$ or $(\mathrm{GCSF})_{2} L \alpha$ in PBS, pH 7.4.

We evaluated two scenarios: when the GCSF dimers bind to the receptor with a ratio of $1: 1$, and 1:2, respectively. To perform a more accurate analysis of such protein association kinetics the generalized Langmuir equation, which accounts for steric exclusion and irreversibility, was developed (Schaaf and Talbot 1989) and later applied to the estimation of protein adsorption on solid surfaces (Jin et al., 1994).In this research we apply a similar approach to describe the interaction of immobilized GCSF-R with (GCSF) ${ }_{2} \mathrm{~L} \alpha$. 
I. Plikusiene, Z. Balevicius, A. Ramanaviciene, J. Talbot, G. Mickiene, S. Balevicius, A. Stirke, A. Tereshchenko, L. Tamosaitis, G. Zvirblis, A. Ramanavicius, Evaluation of affinity sensor response kinetics towards dimeric ligands linked with spacers of different rigidity: Immobilized recombinant granulocyte colony-stimulating factor based synthetic receptor binding with genetically engineered dimeric analyte d. Biosens. Bioelectron. 156, 112112 (2020). doi: https://doi.org/10.1016/j.bios.2020.112112

Journal version is available:

https://www.sciencedirect.com/science/article/abs/pii/S0956566320301093

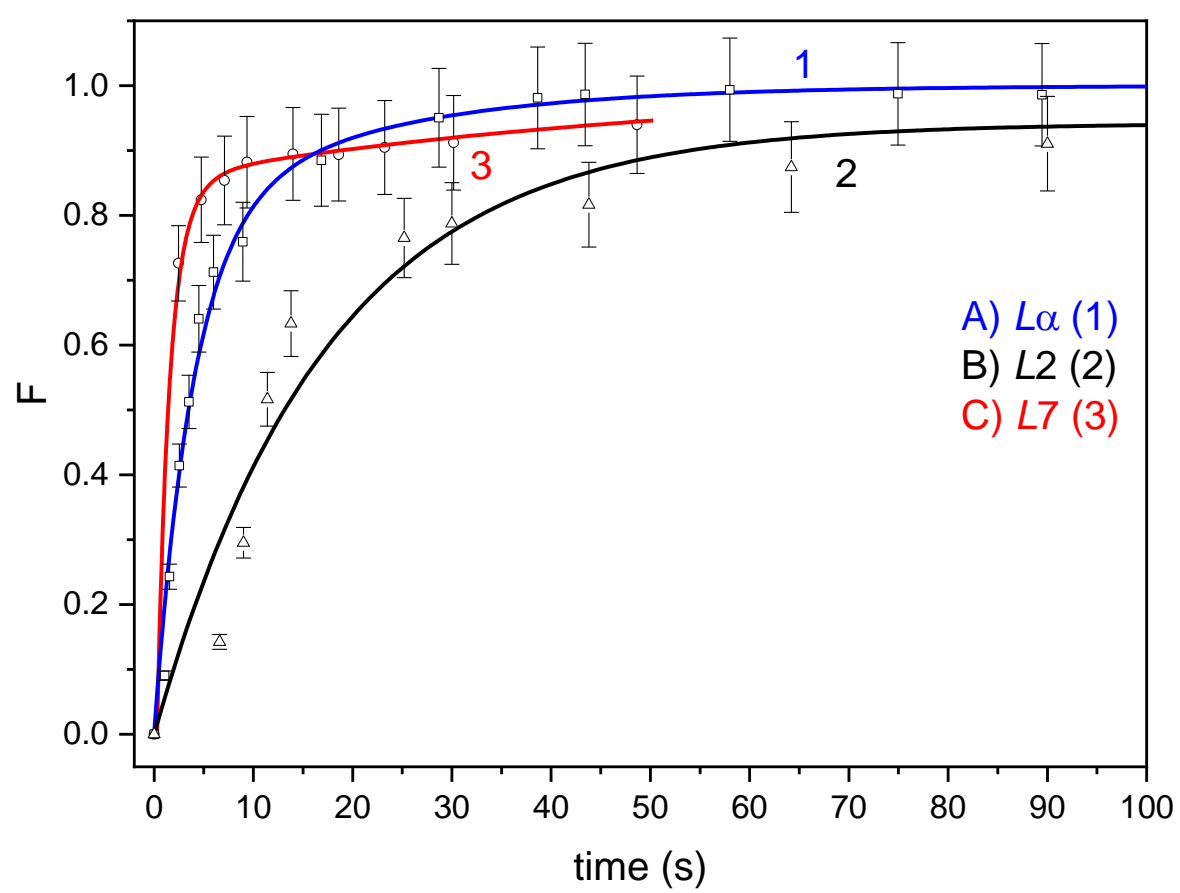

Figure 4. Experimental points and fitting results registered by TIRE-based measurements obtained during the binding of BK7-glass/Cr-Au/MUA/protein-G/HSA\&GCSF-R structure: (i) $(\mathrm{GCSF})_{2} L \alpha$ experimental measurements indicated by squares, blue line (curve 1$)$ represents fitting results, (ii) $(\mathrm{GCSF})_{2} \mathrm{~L} 2$ experimental measurements indicated by triangles, black line (curve 2) - fitting results, (iii) $(\mathrm{GCSF})_{2} L 7$ experimental measurements results indicated by dots, red line (curve 3) - fitting results. The estimated standard deviation of experimental results was calculated as $14 \%$.

The influence of possible non-specific binding of $(\mathrm{GCSF})_{2} L 2,(\mathrm{GCSF})_{2} L 7$ and $(\mathrm{GCSF})_{2} L \alpha$ on protein-based structures was reduced by human serum albumin (HSA), which was mixed with proteins, as described in our previous work (Balevicius et. at 2014). The conditions of TIRE measurements during the evaluation of interaction of $(\mathrm{GCSF})_{2} L 2$, $(\mathrm{GCSF})_{2} L 7$ and (GCSF) ${ }_{2} L \alpha$ with BK7-glass/Cr-Au/MUA/protein-G/HSA\&GCSF-R structure 
I. Plikusiene, Z. Balevicius, A. Ramanaviciene, J. Talbot, G. Mickiene, S. Balevicius, A. Stirke, A. Tereshchenko, L. Tamosaitis, G. Zvirblis, A. Ramanavicius, Evaluation of affinity sensor response kinetics towards dimeric ligands linked with spacers of different rigidity: Immobilized recombinant granulocyte colony-stimulating factor based synthetic receptor binding with genetically engineered dimeric analyte d. Biosens. Bioelectron. 156, 112112 (2020). doi: https://doi.org/10.1016/j.bios.2020.112112

Journal version is available:

https://www.sciencedirect.com/science/article/abs/pii/S0956566320301093

were also similar to that applied for the evaluation of interaction of (GCSF) $)_{2} L 2,(\mathrm{GCSF})_{2} L 7$ and (GCSF) $)_{2} L \alpha$ with BK7-glass/Cr-Au/MUA/Protein-G/HSA\&GCSF-R.

Assessment of experimental results (Fig. 5) shows that a fraction of initially associated proteins $(\mathrm{GCSF})_{2} L \mathrm{X}$ has dissociated from BK7-glass/Cr-Au/MUA/protein-G/HSA\&GCSF-R surface. This effect is attributed to consecutive association kinetics, which is describing protein interaction process where initially (GCSF-R)-(GCSF $)_{2} L 7$ or $(\mathrm{GCSF}-\mathrm{R})-(\mathrm{GCSF})_{2} L \alpha$ complexes ((GCSF-R)-(GCSF) $\left.{ }_{2} L X^{*}\right)$, where single receptor site is bounded to double-sided $(\mathrm{GCSF})_{2} L \mathrm{X}$ ligand, during the next phase (GCSF-R)-(GCSF) ${ }_{2} L X^{*}$ binds with the second GCSF-R receptor site and forms $(\mathrm{GCSF}-\mathrm{R})_{2}=(\mathrm{GCSF})_{2} L X^{*}$ complex, and finally it transforms into a more stable complex (GCSF-R $)_{2} /(\mathrm{GCSF})_{2} L X^{*}$, which does not dissociate under experimental conditions (Stage 3).

This means that a fraction of the $(\mathrm{GCSF}-\mathrm{R})_{2}=(\mathrm{GCSF})_{2} L X^{*}$ complexes, which were formed during the interaction of immobilized receptor GCSF- $R$ with corresponding $(\mathrm{GCSF})_{2}$ $L X$, reorganize into more stable (GCSF-R $)_{2} / /(\mathrm{GCSF})_{2} L X^{*}$ complexes. In these complexes, the interaction between GCSF-R and $(\mathrm{GCSF})_{2} L X$ proteins is much stronger due to partial unfolding of the proteins and better steric adjustment of interacting protein structures, what is leading towards advanced interaction of corresponding (GCSF) $)_{2} L X$ protein with GCSF-R receptor.As a result stronger $(\mathrm{GCSF}-\mathrm{R})_{2} / /(\mathrm{GCSF})_{2} L \mathrm{X}$ complexes are formed on the surface of BK7-glass/Cr-Au/MUA/protein-G/HSA\&GCSF-R. The replacement of the solution, which contains bindable (GCSF) ${ }_{2} L X$ proteins, by pure buffer solution leads to the dissociation of the fraction of protein complexes (GCSF-R)-(GCSF) ${ }_{2} L X^{*}$ formed during the incubation of BK7glass/Cr-Au/MUA/protein-G/HSA\&GCSF-R structure in $(\mathrm{GCSF})_{2} L 2, \quad(\mathrm{GCSF})_{2} L 7$ or $(\mathrm{GCSF})_{2} L \alpha$ containing solution. This effect is observed from the different changes of ellipsometric parameters calculated for the interaction of $(\mathrm{GCSF})_{2} L 2,(\mathrm{GCSF})_{2} L 7$ or $(\mathrm{GCSF})_{2} L \alpha$ (Fig. 5) during rinsing with pure buffer solution. It is reasonable to assume that a different decrease of the ellipsometric signals indicates different association/dissociation constants for the binding of immobilized receptor GCSF-R with homo-dimeric derivatives 
I. Plikusiene, Z. Balevicius, A. Ramanaviciene, J. Talbot, G. Mickiene, S. Balevicius, A. Stirke, A. Tereshchenko, L. Tamosaitis, G. Zvirblis, A. Ramanavicius, Evaluation of affinity sensor response kinetics towards dimeric ligands linked with spacers of different rigidity: Immobilized recombinant granulocyte colony-stimulating factor based synthetic receptor binding with genetically engineered dimeric analyte d. Biosens. Bioelectron. 156, 112112 (2020). doi: https://doi.org/10.1016/j.bios.2020.112112

Journal version is available:

https://www.sciencedirect.com/science/article/abs/pii/S0956566320301093

$(\mathrm{GCSF})_{2} L 2,(\mathrm{GCSF})_{2} L 7$ or $(\mathrm{GCSF})_{2} L \alpha$ in which GCSF units are connected with linkers of different length and/or structure.

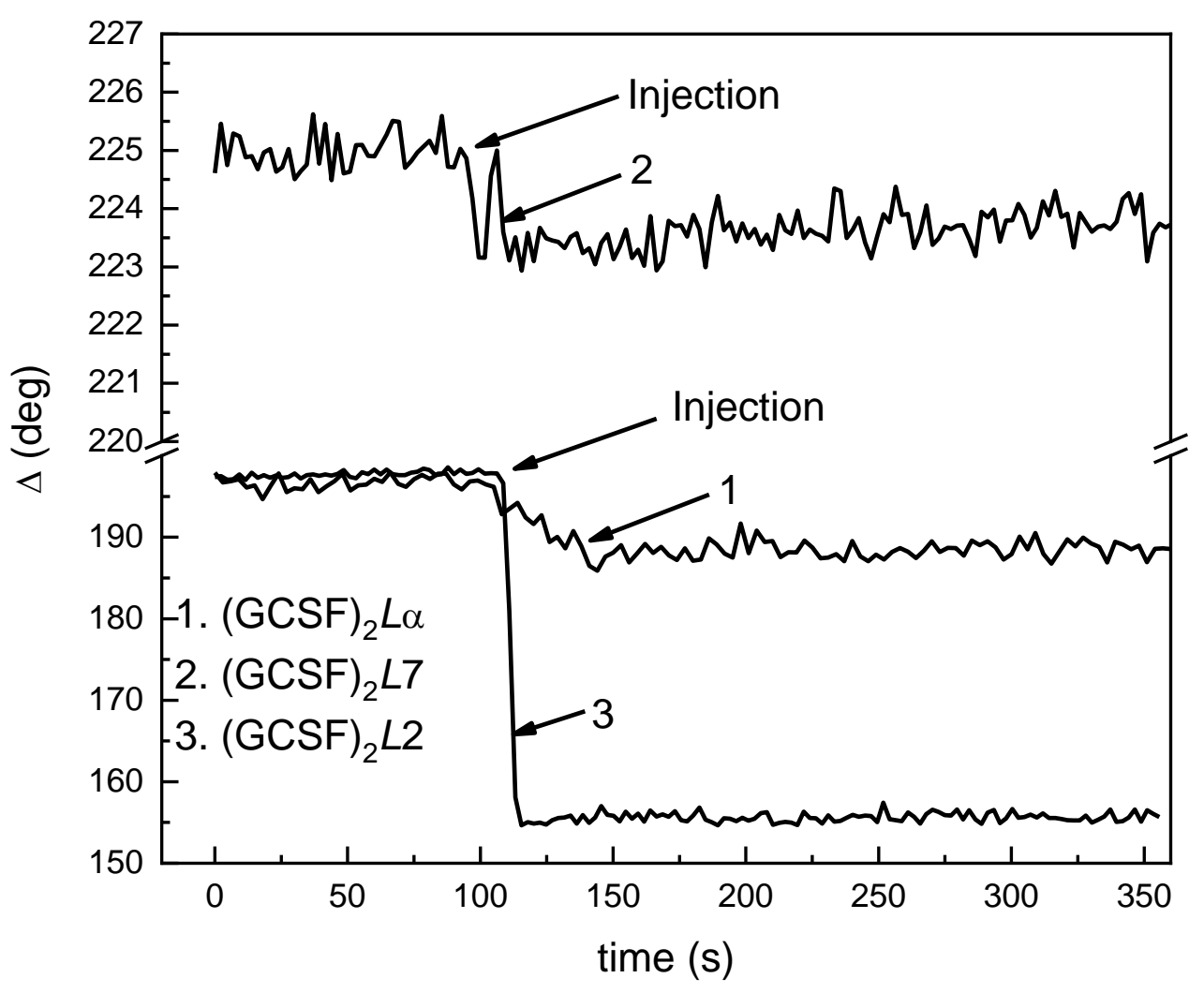

Figure 5. The evaluation of ellipsometric parameter ' $\Delta$ ' vs for GCSF-based derivatives: 1) $\left.\left.(\mathrm{GCSF})_{2} L \alpha ; 2\right)(\mathrm{GCSF})_{2} L 7 ; 3\right)(\mathrm{GCSF})_{2} L 2$, during the dissociation phase.

Additionally, the influence of non-specific binding of $(\mathrm{GCSF})_{2} L 2,(\mathrm{GCSF})_{2} L 7$ and $(\mathrm{GCSF})_{2} L \alpha$ on protein-based structures has been evaluated. For this HSA-modified structure BK7-glass/Cr-Au/MUA/Protein-G/HSA - was tested instead of receptor-modified structure BK7-glass/Cr-Au/MUA/Protein-G/HSA\&GCSF-R at the same conditions (Balevicius et al., 2014). In all these cases the change of ellipsometric parameters for the binding kinetics was 
I. Plikusiene, Z. Balevicius, A. Ramanaviciene, J. Talbot, G. Mickiene, S. Balevicius, A. Stirke, A. Tereshchenko, L. Tamosaitis, G. Zvirblis, A. Ramanavicius, Evaluation of affinity sensor response kinetics towards dimeric ligands linked with spacers of different rigidity: Immobilized recombinant granulocyte colony-stimulating factor based synthetic receptor binding with genetically engineered dimeric analyte d. Biosens. Bioelectron. 156, 112112 (2020). doi: https://doi.org/10.1016/j.bios.2020.112112

Journal version is available:

https://www.sciencedirect.com/science/article/abs/pii/S0956566320301093

negligible and within he signal-to-noise level. Therefore, non-specific interaction during the evaluation of here evaluated binding kinetics is neglected.

We previously reported in vivo and in vitro investigations of GCSF ligands linked with different spacers (Mickiene et al., 2017). The interaction-ability of the bidentate G-CSF-based ligands in vitro was determined using a cell proliferation assay with the G-CSF dependent cell line M-NFS-60. The G-CSF monomer was used as a reference mono-dentate ligand. In vitro the interaction between G-CSF-Receptor and several bidentate G-CSF-based ligands was evaluated by spectrometric determination of the coloured formazan product formed during the cleavage of tetrazolium salt (MTS) by viable cells. In this case, calculated in vitro activity of $(\mathrm{GCSF})_{2} L \alpha$ reached $48 \%$ of that of the G-CSF monomer, while (GCSF) $)_{2} L 2$ and $(\mathrm{GCSF})_{2} L 7$ demonstrated relative activities of $22 \%$. The in vivo (in healthy rats) response, i.e., the ability of G-CSF-based ligands to stimulate neutrophil release, was more pronounced for $(\mathrm{GCSF})_{2} L \alpha$ compared to the monomeric GCSF ligand. After $24 \mathrm{~h}$ of a single subcutaneous injection of $(\mathrm{GCSF})_{2} L \alpha$, rats exhibited a 1.8 -fold increase in circulating neutrophils, albeit with a larger margin of error. (GCSF) $)_{2} L \alpha$ had the best performance in terms of purity and in vitro activity. However, the primary idea on the ability of $(\mathrm{GCSF})_{2} L \alpha$ to activate the receptor with a higher efficiency was not confirmed because the dimer has the same efficiency as the G-CSF monomer in vitro. In this research the $L 2$ and $L 7$ linkers, which consisted of stretches of Gly and Ser residues, implemented greater degrees of freedom in the overall conformation, whereas the $L \alpha$ linker had a more rigid, helical-alpha, spiral-like structure (Yamasaki et al., 2008, Chen et al., 2013, Chichili et al., 2013). Hence, our previous research (Mickiene et al., 2017) illustrates that the interaction-ability of the genetically engineered 'bidentate G-CSF-based ligands' depends on the length and the rigidity of the linker, which interconnects both G-CSF units.

The reaction mechanism of molecules depends on the length and the structure of the linker connecting the two monomers. It has an impact on the molecules' activity. In vitro activity of the G-CSF dimers was determined using a cell proliferation assay with the G-CSF dependent cell line M-NFS-60. The G-CSF monomer was used as a reference. Results were 
I. Plikusiene, Z. Balevicius, A. Ramanaviciene, J. Talbot, G. Mickiene, S. Balevicius, A. Stirke, A. Tereshchenko, L. Tamosaitis, G. Zvirblis, A. Ramanavicius, Evaluation of affinity sensor response kinetics towards dimeric ligands linked with spacers of different rigidity: Immobilized recombinant granulocyte colony-stimulating factor based synthetic receptor binding with genetically engineered dimeric analyte d. Biosens. Bioelectron. 156, 112112 (2020). doi: https://doi.org/10.1016/j.bios.2020.112112

Journal version is available:

https://www.sciencedirect.com/science/article/abs/pii/S0956566320301093

obtained by absorbance readings of the coloured formazan product accessed by the cleavage of tetrazolium salt (MTS) by viable cells. Calculated in vitro activity of GCSF-La reached $48 \%$ of that of the G-CSF monomer, while GCSF-L2 and GCSF-L7 demonstrated relative activities of $22 \%$.

The in vivo (in healthy rats) response, which comprised the ability of G-CSF to stimulate neutrophil release, was more pronounced for GCSF-La compared to the monomeric protein. After $24 \mathrm{~h}$ of a single subcutaneous injection of GCSF-La, rats exhibited a 1.8-fold increase in circulating neutrophils, albeit with a larger margin of error. GCSF-La had the best performance in terms of purity and in vitro activity. However, the primary idea on the ability of GCSF-La to activate the receptor with higher efficiency was not confirmed as the dimer acted as the G-CSF monomer in vitro (Mickieke et. al., 2017) 
I. Plikusiene, Z. Balevicius, A. Ramanaviciene, J. Talbot, G. Mickiene, S. Balevicius, A. Stirke, A. Tereshchenko, L. Tamosaitis, G. Zvirblis, A. Ramanavicius, Evaluation of affinity sensor response kinetics towards dimeric ligands linked with spacers of different rigidity: Immobilized recombinant granulocyte colony-stimulating factor based synthetic receptor binding with genetically engineered dimeric analyte d. Biosens. Bioelectron. 156, 112112 (2020). doi: https://doi.org/10.1016/j.bios.2020.112112

Journal version is available:

https://www.sciencedirect.com/science/article/abs/pii/S0956566320301093

\section{Conclusions}

Kinetic studies of bidentate homo-dimeric (GCSF) $)_{2} L X$ ligand binding to immobilized GCSF$\mathrm{R}$ receptor show that structural features of the linker connecting two GCSF molecules strongly influence the association rate and the possibility of irreversible binding of these homo-dimeric $(\mathrm{GCSF})_{2} L X$ ligands to the GCSF-R receptors. The binding of (GCSF) $)_{2} L 2$ to immobilized GCSF-R is well described by the conventional Langmuir equation, while the kinetics of $(\mathrm{GCSF})_{2} L 7$ and (GCSF) $)_{2} L \alpha$ binding is best described by a three step consecutive kinetics model with irreversible last step of rearrangement. The comparison of association rates of homodimeric derivatives $(\mathrm{GCSF})_{2} L 2$ and $(\mathrm{GCSF})_{2} L 7$ demonstrates that the $(\mathrm{GCSF})_{2} L 2$ derivative, with its short linker compared to the distance between GCSF-R receptor sites, was characterized by lower association rate then that determined during the binding with $(\mathrm{GCSF})_{2} L 7$ ligand, where a longer linker - L7 - was applied. The binding rate of the $(\mathrm{GCSF})_{2} L 7$ derivative to immobilized GCSF-R is about two times higher than that of the conventional GCSF monomer derivative. Moreover, after rearrangement, the $(\mathrm{GCSF})_{2} L 7$ molecules are able to create a stable, non-dissociable structure with GCSF-R receptor. However, the $(\mathrm{GCSF})_{2} L \alpha$ is also able to bind irreversibly with GCSF-R receptor. Therefore, the binding rate of $(\mathrm{GCSF})_{2} L \alpha$ derivative is 2 times higher than that of $(\mathrm{GCSF})_{2} L 2$ molecules, but it is still 2 and 3.5 times lower in comparison to that of the monomeric GCSF ligand and the dimeric ligand $-(\mathrm{GCSF})_{2} L 7$, respectively. Due to better binding, homo-dimeric $(\mathrm{GCSF})_{2} L \alpha$ and $(\mathrm{GCSF})_{2} L 7$ derivatives are good candidates for new GCSF-based drugs, which are structurally novel compared to currently commercially available GCSF-based analogues.

\section{Acknowledgement}


I. Plikusiene, Z. Balevicius, A. Ramanaviciene, J. Talbot, G. Mickiene, S. Balevicius, A. Stirke, A. Tereshchenko, L. Tamosaitis, G. Zvirblis, A. Ramanavicius, Evaluation of affinity sensor response kinetics towards dimeric ligands linked with spacers of different rigidity: Immobilized recombinant granulocyte colony-stimulating factor based synthetic receptor binding with genetically engineered dimeric analyte d. Biosens. Bioelectron. 156, 112112 (2020). doi: https://doi.org/10.1016/j.bios.2020.112112

Journal version is available:

https://www.sciencedirect.com/science/article/abs/pii/S0956566320301093

This research was supported by Ukrainian-Lithuanian Research project "Application of hybrid nanostructures which are based on $\mathrm{TiO}_{2}$ or $\mathrm{ZnO}$ and modified by biomolecules, in optoelectronic sensors" Lithuanian Research Council project No P-LU-18-53. 
I. Plikusiene, Z. Balevicius, A. Ramanaviciene, J. Talbot, G. Mickiene, S. Balevicius, A. Stirke, A. Tereshchenko, L. Tamosaitis, G. Zvirblis, A. Ramanavicius, Evaluation of affinity sensor response kinetics towards dimeric ligands linked with spacers of different rigidity: Immobilized recombinant granulocyte colony-stimulating factor based synthetic receptor binding with genetically engineered dimeric analyte d. Biosens. Bioelectron. 156, 112112 (2020). doi: https://doi.org/10.1016/j.bios.2020.112112

Journal version is available:

https://www.sciencedirect.com/science/article/abs/pii/S0956566320301093

\section{References}

Arai, R., Ueda, H., Kitayama, A., Kamiya, N., Nagamune, T., 2001. Protein Eng. 14, 529-532.

Arwin H., 2014. Springer, Ellipsom. of func. organ. surf. and films. Chapter 2, 12, 249.

Arwin H., Poksinski M., Johansen K. 2008. Phys. Status Solidi A. 205, 817-820.

Balevicius, Z., Makaraviciute, A., Babonas, G.J., Tumenas, S., Bukauskas, V., Ramanaviciene, A., Ramanavicius, A., 2013. Sens. Actuators B Chem. 18, 119-124.

Balevicius, Z., Baleviciute, I., Tumenas, S., Tamosaitis, L., Stirke, A., Makaraviciute, A., Ramanaviciene, A., Ramanavicius, A., 2014. Thin Solid Films. 571, 744-748.

Balevicius, Z., Talbot, J., Tamosaitis, L., Plikusiene, I., Stirke, A, Mickiene, G., Balevicius, S., Paulauskas, A., Ramanavicius, A., 2019. Sens. Actuators B Chem. 297, 126770.

Baleviciute, I., Balevicius, Z., Makaraviciute, A., Ramanaviciene, A., Ramanavicius, A., 2013. Biosens. Bioelectron. 39, 170-176.

Berlind, T., Poksinski, M., Tengvall, P., Arwin, H., 2010. Colloids Surf. B. 75, 41.

Chen, X., Lee, H.-F., Zaro, J.L., Shen, W.C., 2011. Mol. Pharm. 8, 457-465.

Chen, X., Zaro, J. L., Shen, W. C., 2013. Adv. Drug. Deliv. Rev. 65,1357-1369.

Chichili, R., Kumar, V. P., Sivaraman, J., 2013. Protein Sci. 22, 153-16

Huggett, B., Hodgson, J., Lahteenmaki, R., 2011. Nat. Biotechnol. 29, 585-591.

Jin, X., Talbot, J., Wang, N.H.L., 1994. AIChE J. 40, 1685-1696.

Nabok, A., Tsagodorskaya, A., Hassan, A. K., Starodub, N. F, 2005. Appl. Surf. Sci. 246, 381386.

Mickiene, G., Dalgediene, I., Dapkunas, Z., Zvirblis, G., Pesliakas, H., Kaupinis, A., Valius, M., Mistiniene, E., Pleckaityte, M., 2017. Mol. Biotechnol. 59, 374-384.

Mitchell, A.C., Briquez, P.S., Hubbell, J.A., Cochran, J.R., 2016. Acta Biomater. 30, 1-12.

Moirangthem, R.S, Chang, Y.C, Hsu, S.H, Wei, P.K., 2010. Biosens. Bioelectron. 25, 2633-8

Poksinski, M., Arwin, H., 2004. Thin Sol. Fims. 716, 455-456.

Ramanavicius, A., Oztekin, Y., Ramanaviciene, A., 2014. Sens. Actuators B Chem. 197, 237243. 
I. Plikusiene, Z. Balevicius, A. Ramanaviciene, J. Talbot, G. Mickiene, S. Balevicius, A. Stirke, A. Tereshchenko, L. Tamosaitis, G. Zvirblis, A. Ramanavicius, Evaluation of affinity sensor response kinetics towards dimeric ligands linked with spacers of different rigidity: Immobilized recombinant granulocyte colony-stimulating factor based synthetic receptor binding with genetically engineered dimeric analyte d. Biosens. Bioelectron. 156, 112112 (2020). doi: https://doi.org/10.1016/j.bios.2020.112112

Journal version is available:

https://www.sciencedirect.com/science/article/abs/pii/S0956566320301093

Scholz, M., Engel, C., Apt, D., Sankar, S.L., Goldstein, E., Loeffler, M., 2009. Cell Prolif. 42, 823-837.

Tamada, T., Honjo, E., Maeda, Y., Okamoto, T., Ishibashi, M., Tokunaga, M., Kuroki, R., 2006. Proc. Natl. Acad. Sci. USA. 103, 3135-3140.

Talbot, J., 1996. Adsorption. 2, 89-94.

Yamasaki, M., Konishi, N., Yamaguchi, K., Itoh, S., Yokoo, Y., 1998. Biosci. Biotechnol. Biochem. 62, 1528-1534 